\title{
التحكيم في الصفقات العمومية بين الرفض والتأييا ـ دراسة مقارنة
}

The arbitrage in public transactions between refusal and support- a comparative study

تاريخ الاستلام:2019/03/04؛تاريخ القبول:2019/04/23

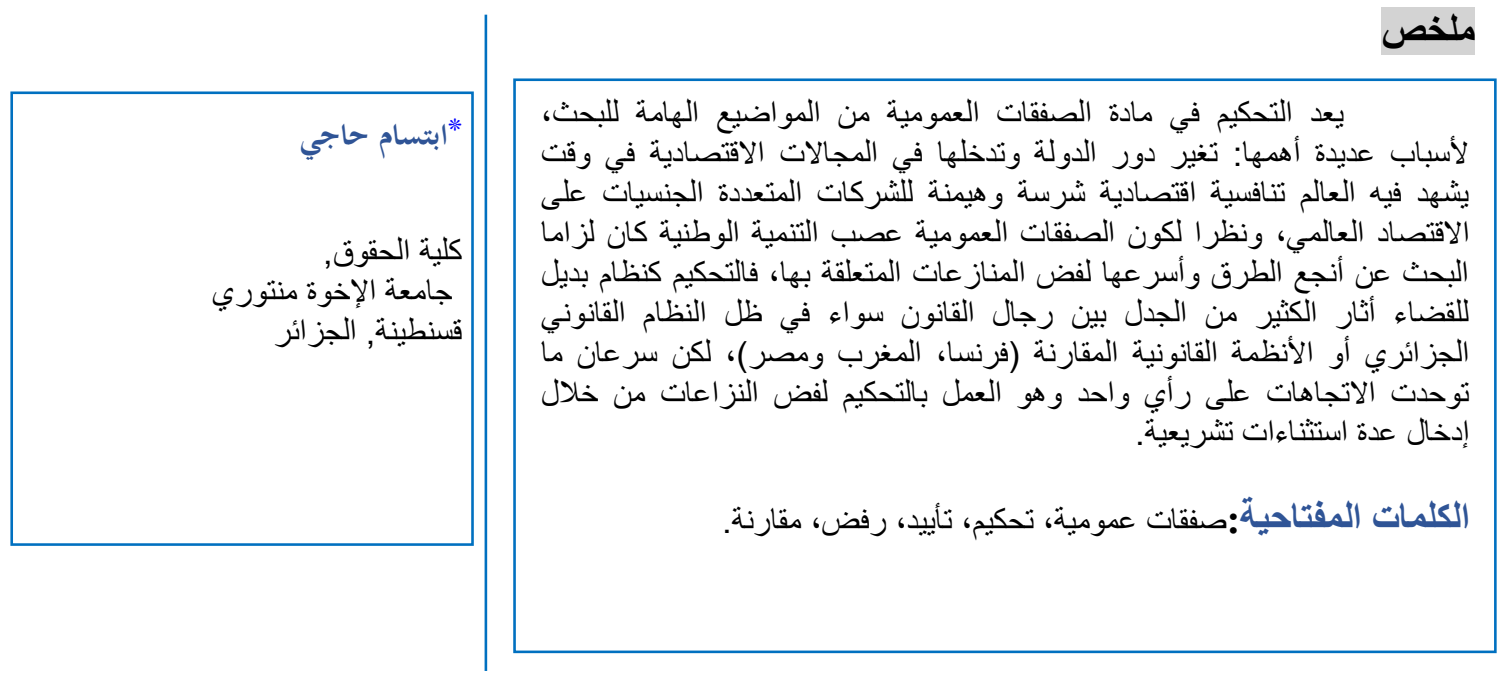

\section{Abstract}

The arbitrage in public transactions is an important subject mostly because the change of state's role and its intervention in economic domain at a time when the world is facing a fierce economic competitiveness and the multinational company's domination on the world's economic. Because the public transactions are the backbone of the national development, it was very important to search the most efficient and the fastest way in order to settlement the conflicts. The arbitration of as a legal order causes a lot of controversy among the jurists, whether under Algerian legal or comparative one like that belongs to French, Moroccan and Egyptian. But there is no longer time when the trends have merged into one mind, such as working with the arbitration in order to settlement the conflicts and introducing legislative exceptions.

Keywords:public transaction, arbitrage, rejection, support, comparaison

\section{Résumé}

L'arbitrage dans les transactions publiques est un sujet important surtout en raison du changement du rôle d'état et de son intervention dans le domaine économique en un temps où le monde fait face à une compétitivité économique féroce et à la domination de la compagnie multinationale sur le monde économique. Puisque les transactions publiques sont la colonne vertébrale du développement national, il était très important de chercher la voie la plus efficace et la plus rapide pour régler les conflits. L'arbitrage en temps que système alternative à la justice provoque beaucoup de controverse parmi les juristes, que ce soi dans le système juridique Algérien ou comparé tel que le Français, Marocain et l'Egyptien. Mais pas un long le temps où les tendances se sont convergé dans un seul esprit, tel que l'adaptation de l'arbitrage pour régler les conflits via l'introduction des exceptions législatives.

Mots clés:marché public,arbitrage, refus, acceptation, comparaison.

* Corresponding author, e-mail:hadjidroit@hotmail.fr 
إذا كانت بدايات التحكيم في العقود قد ارتبطت بمجال المنازعات التجارية،

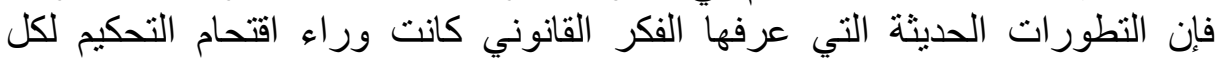

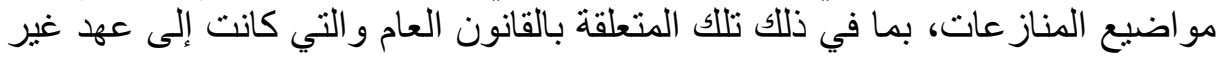

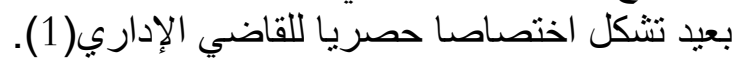

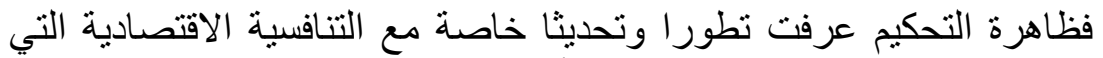

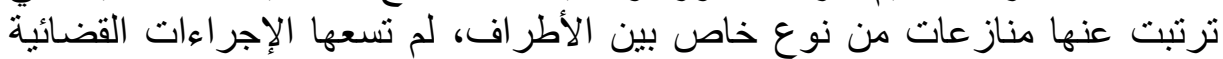

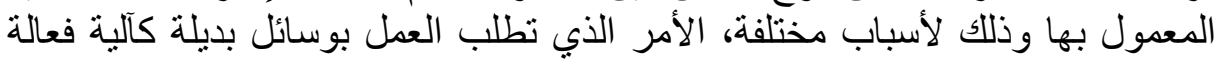

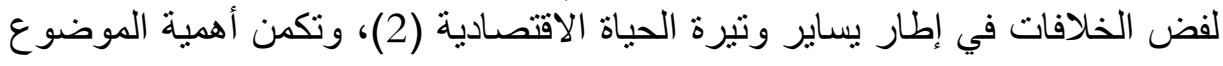

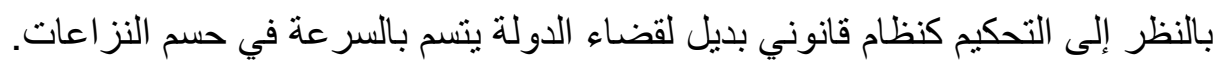

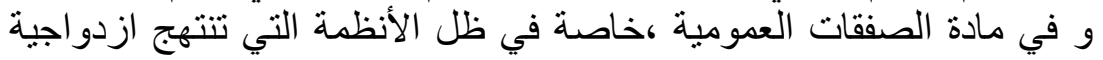

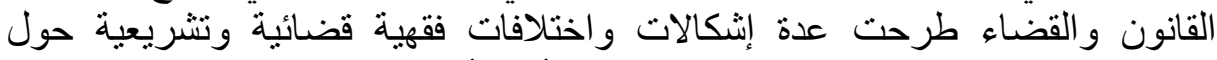

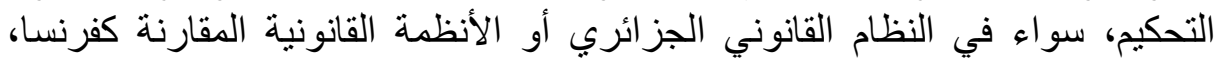

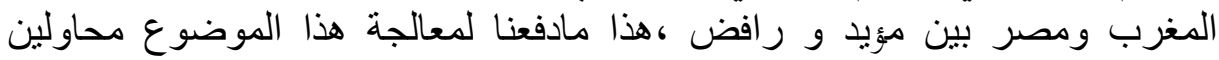

الإجابة على الإشكالية التالية:

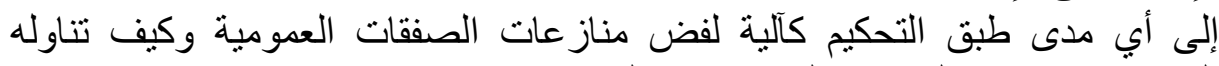

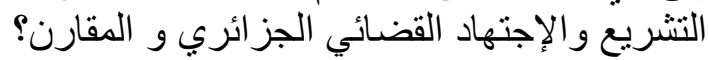

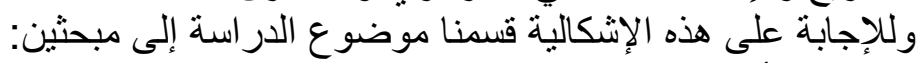

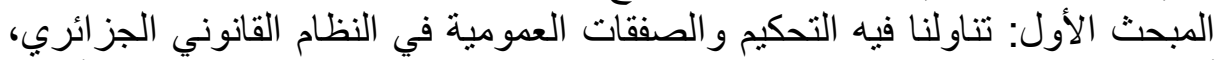

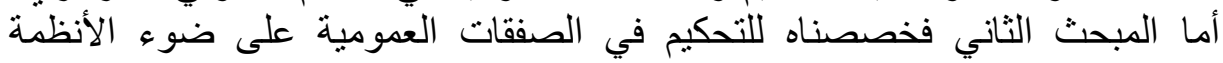
القانونية المقارنة.

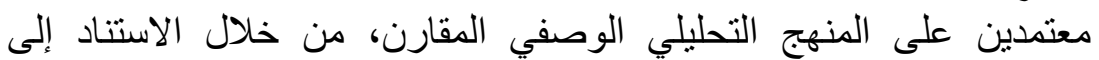

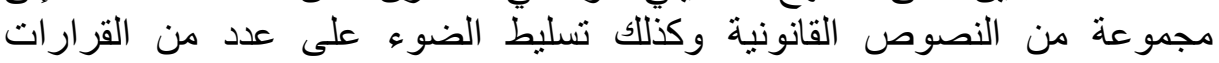

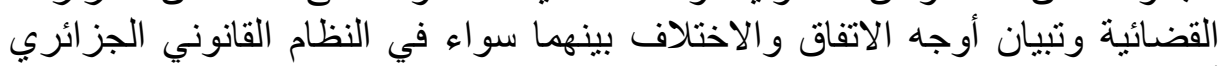
أو المقارن (فرنسا، المغرب ؤبهان ومصر).

\section{المبحث الأول: التحكيم والصفقات العمومية في النظام القانوني الجزائري}

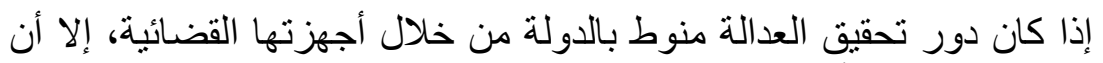

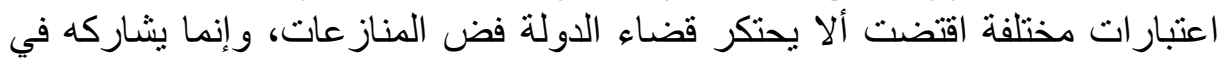

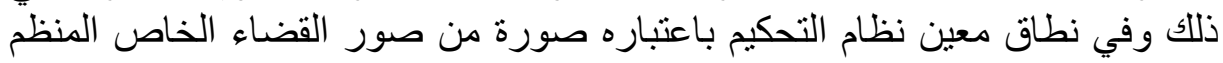

والجزائر شأنها شأن الكثير من الدول عرفت تحولا نوعيا من خلال

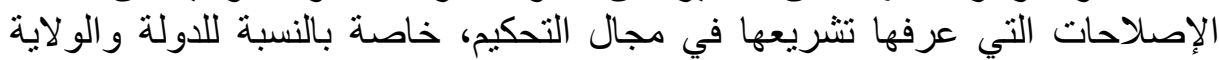

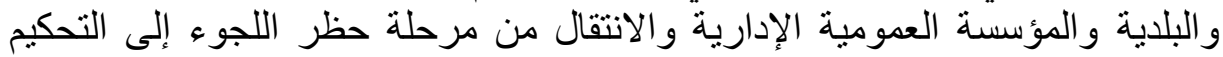

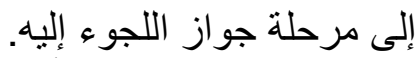

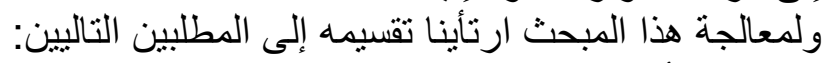

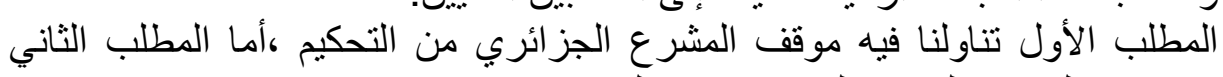
خصصناه لموقف القضاء الجز ائري من التحكيم. 


\section{المطلب الأول: موقف المشرع الجزائري من التحكيم.}

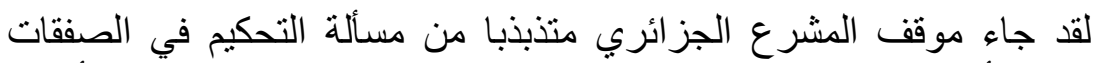

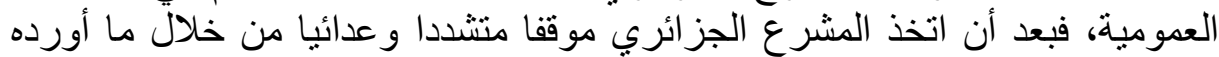

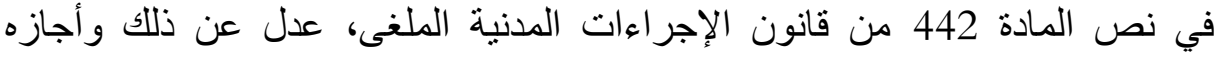
للأشخاص المعنوية العامة وفق ما تضمنته المادة 975 من قانون الإجراءات المدنية و هذا ما سنتاوله من خلال الفرعين التالين:

\section{الفرع الأول :رفض التحكيم.}

من الناحية التاريخية نجد أن المشرع الجزائري تمسك بالموقف الر افض للتحكيم في

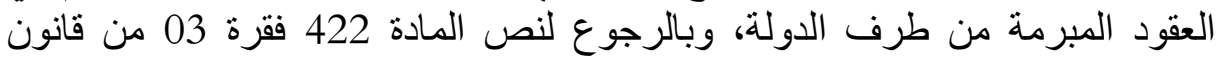

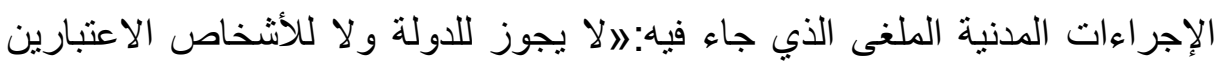

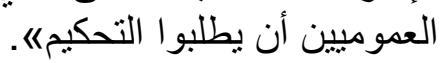

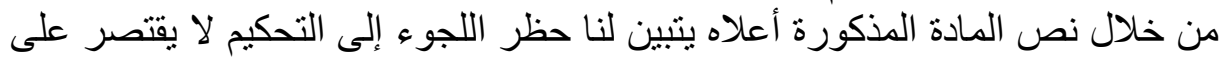

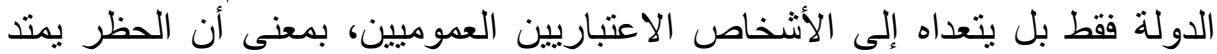

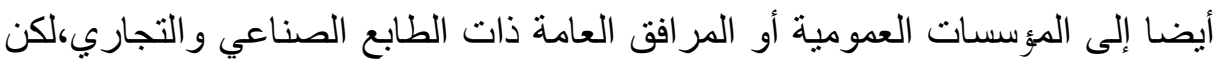

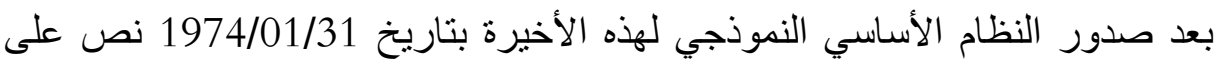
أنها تعمل وفق قو اعد القانون الخاص(3)، بمعنى أجاز لها اللجوء إلى التحكيم. وفي إطار التحولات التي طرأت على الاقتصاد الوطني تم تعديل أحكام التحكيم التحني

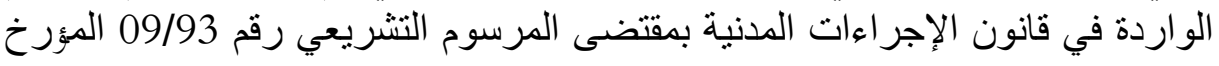

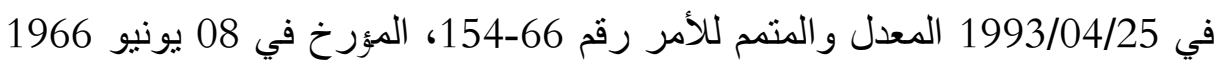
و المتضمن قانون الإجراءات المدنية من خلال السماح للأشخاص المعنوية العامة

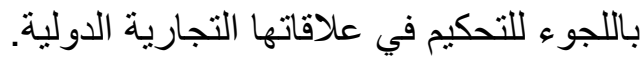

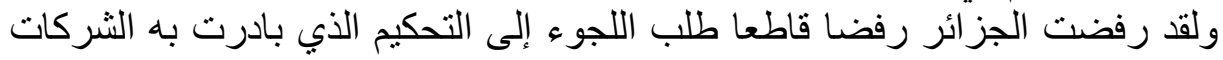
الفرنسية العاملة بها تطبيقا لاتفاقية 1965/07/29 والمتعلقة طلقة بالتعاون في مجال

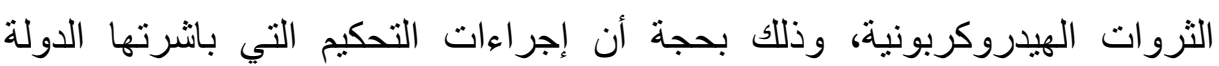

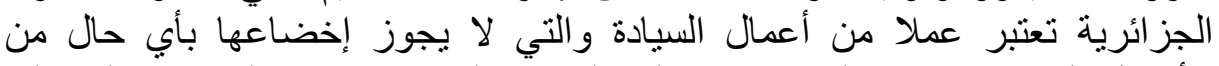

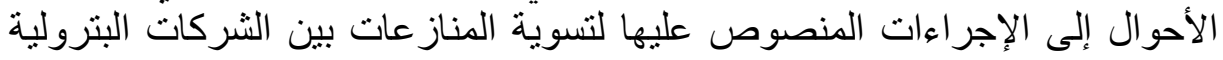
والإدارة الجزائر الإية.

وأمام هذا الأمر لم يبقى أمادة المام الثركات الفرنسية إلا قبول الأمر الواقع وذللك بتوقيع

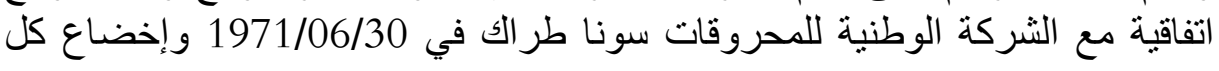

المناز عات للقانون الوطني الجزائري(4).

الفرع الثاني : قبول التحكيم

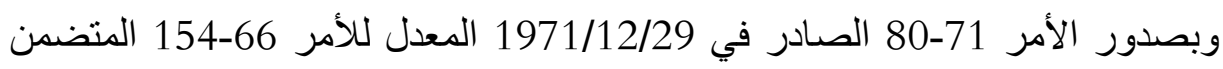
قانون الإجراءات المدنية، أخضع المشرع الجزائري الثركات الوطنية للتحكيم، ثم مد 
نطاقه سنة 1975 إلى كافة المؤسسات التي تملكها الدولة أو تملك أكثر أكثرية رأسمالها.

وبالرجوع للقانون المتعلق بالصفقات العمومية نجد أن موقف المشرع الجزائري جاء

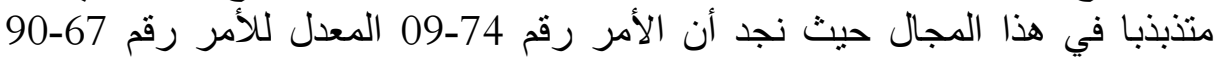

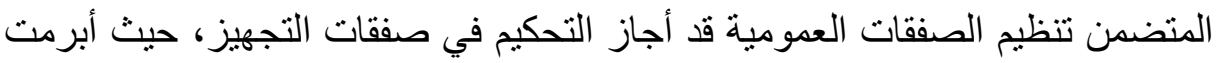

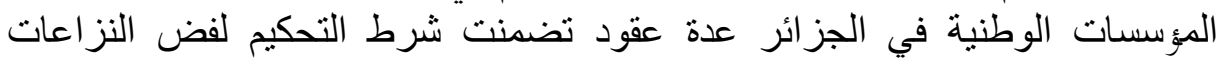
الناشئة أثناء تنفيذ الصفقة، نذكر على سبيل المثال ما نصت عليه المادة 43 من عق"Ruvennacopérativa" و الذي جاء فيه :" يسري هذاء العقد في القانون

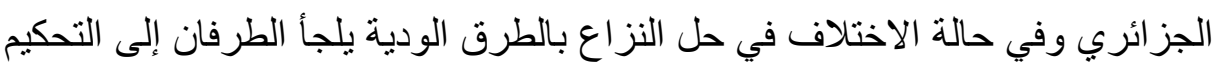

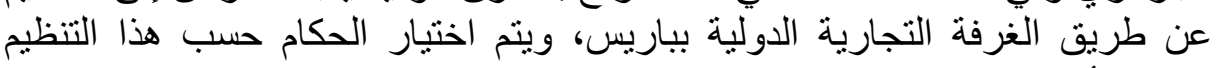

ويفضل أن يكون محل التحكيم بالجزائر «(5).

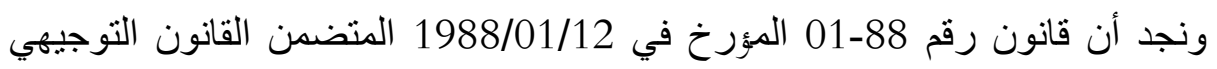

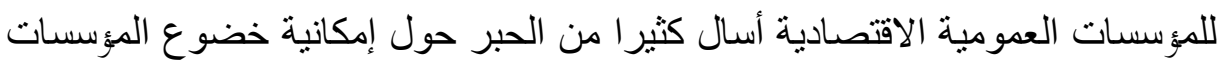

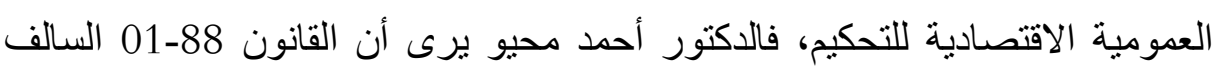
الذكر يسمح صر احة للمؤسسات العمومية الاقتصادية باللجوء للتحكيم و المادة 20 فقرة 04 نرفع كل غموض حول هذه المسألة(6) والتي جاء فيها:/ كما يمكن أن تكون

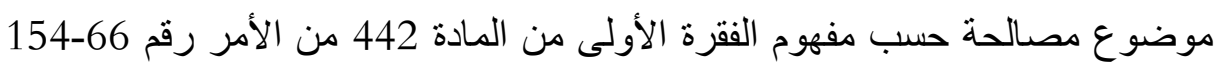
المؤرخ في 8 يونيو 1966 المذكور أعلاهه(7). كما أن القاضي محمد بجاوي يرى أن إحدى القوانين العشرة من بينها قانون رقم 88-

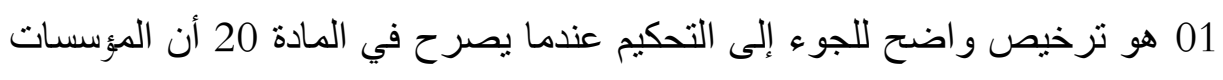

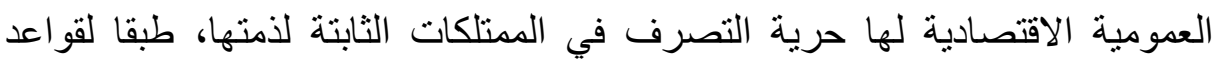

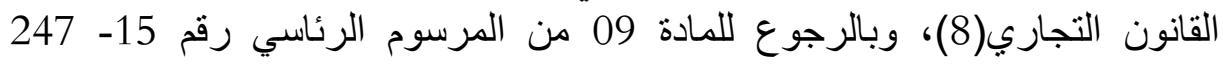

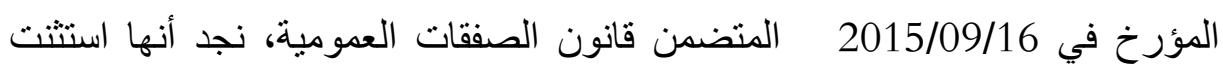
المؤسسات العمومية الاقتصادية من أحكام إبرام الصفقات العمومية.

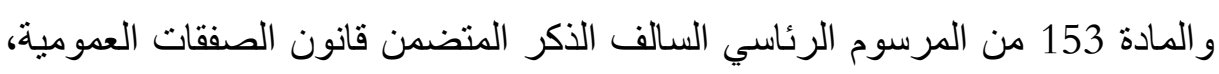

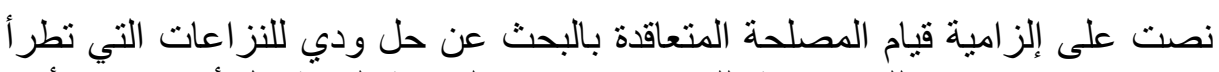

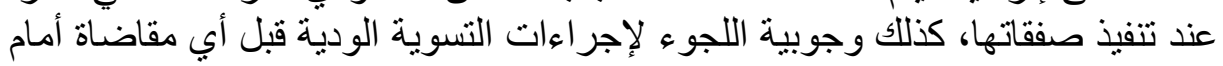
العدالة.

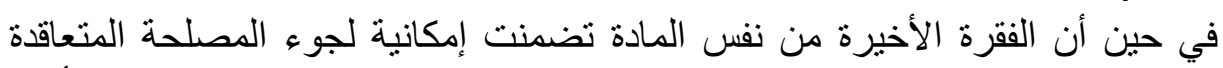

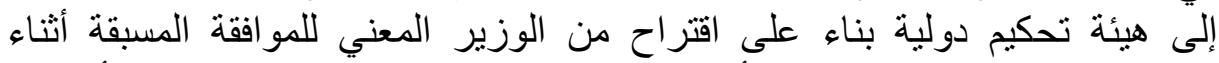

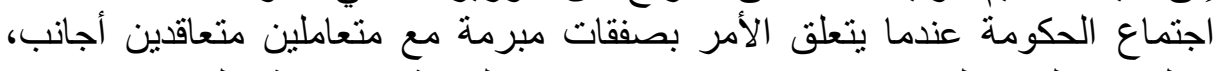

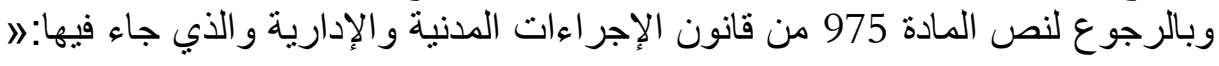

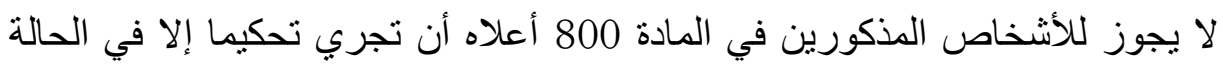

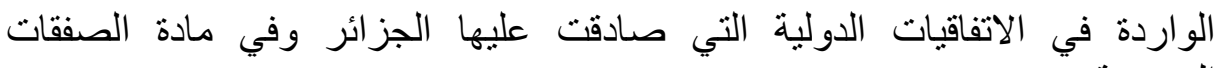
العموميةها. و المادة 1006 من نفس القانون جاء فيها: ا يمكن لكل شخص اللجوء إلى التحكيم في الحقوق التي له مطلق التصرف فيها، لا يجوز التحكيم في المسائل المتعلقة بالنظام 


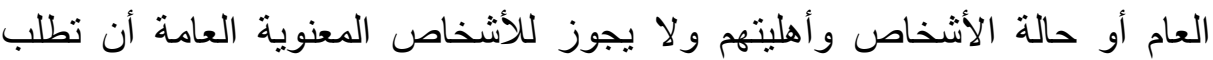

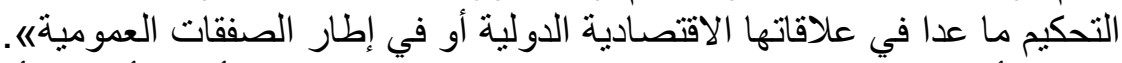

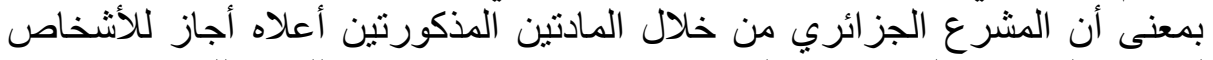

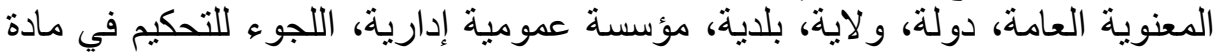

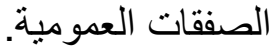
المطلب الثاني: موقف القضاء الجزائري من التحكيم.

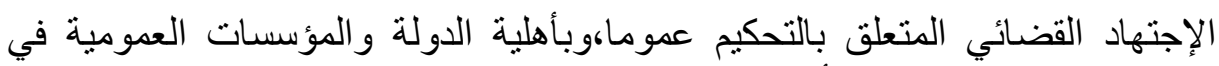

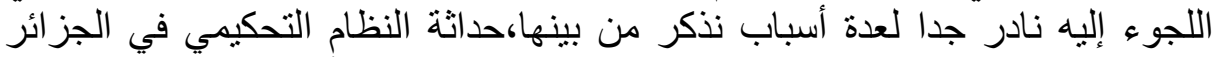

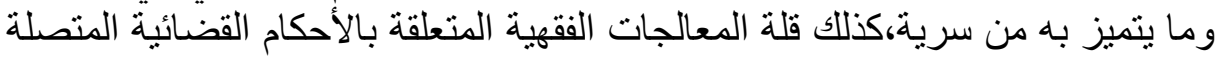

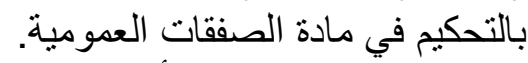
ولمعالجة هذا المطلب ارتأينا تقسيمه إلى الفرمية.

\section{القرع الأول: رفض التحكيم}

لقد ذهب القضاء الجزائري ممثلا في مجلس قضاء الجزائر إلى عدم جواز إدراج إنها

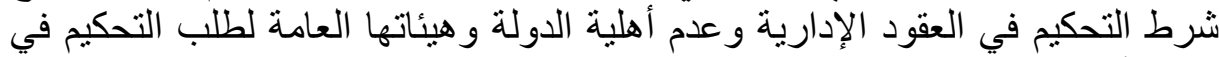
بعض أحكامه نذكر من بينها:

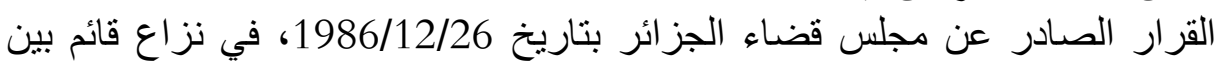
شركة ك.ل ضد المؤسسة العمومية للبناء، حيث تم إبرام عقد بينهما في 1983/05/20

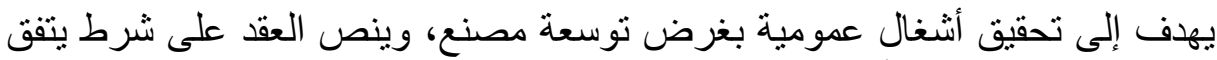

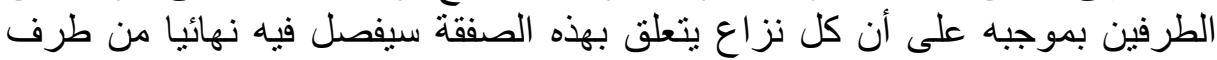

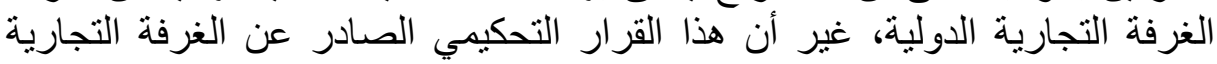

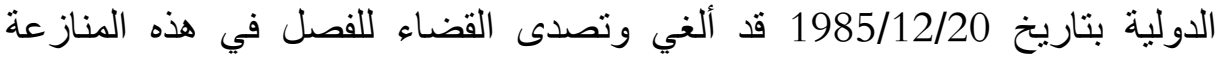

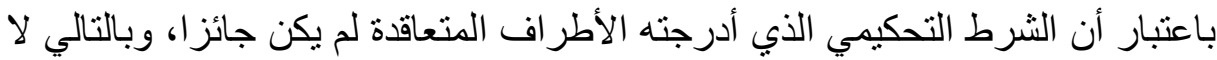

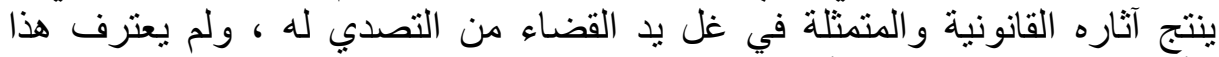

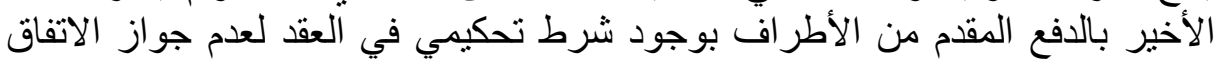

على ذللك(9).

\section{الفرع الثاني :قبول التحكيم}

لم يتخذ القضاء الجزائري موقفا ثابتا من مسألة مدى صحة شرط التهاء التحكيم الصادر من التهاء

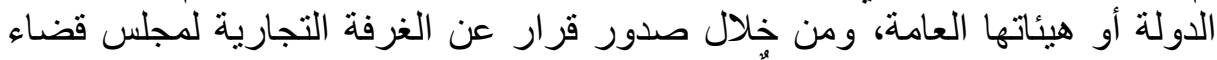

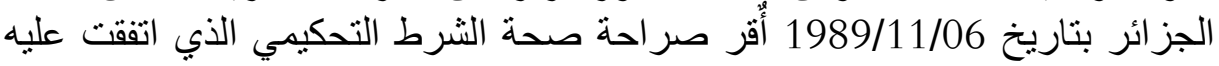

مئسسة عمومية جز ائرية.

بمعنى أن القضاء الجزائري بدأ يتقبل فكرة التحكيم نتيجة للتطورات السياسية، الاقتصادية والقانونية(10).

ويرى بعض الفقه أن مجلس قضاء الجزائر اعترف بصحة اتفاق التحكيم وفقا لنص التص التصاء

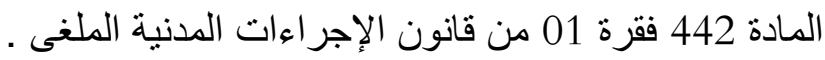
كذلك حكم محكمة الجزائر بتاريخ 1973/05/03، الذي لم تثقيد فيه المحكمة بالمادة 442 فقرة 03 من قانون الإجراءات المدنية وأقرت بصحة شرط التحكيم المبرم من طرف هيئة تابعة للدولة. 
و وتتلخص وقائع هذه القضية كما يلي: تم إبرام عقد بين شركة سونا طر الك وشركة SMC وأراد الأطراف تغيير شروط تسوية النزاعات، لكن قبل أن تتم المفاوضات

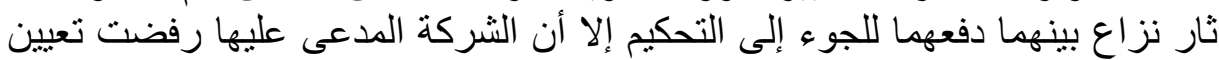

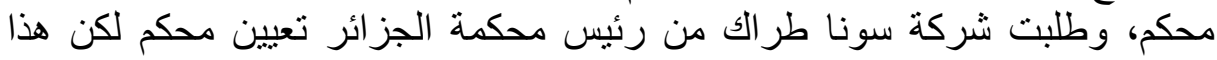
الطلب رفض من قبله، ليس على أساس المادة 442 و التي كان من من المدكن إثارتها و إنما لأسباب أخرى، و هذا معناه قبول ضمن فلهي من المجلس القضائي بشرط التحكيم في العقود الإدارية (11) - (11).

\section{المبحث الثاني: التحكيم في الصفقات العمومية على ضوء الأنظمة القانونية المقارنة}

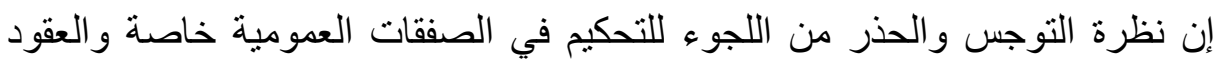

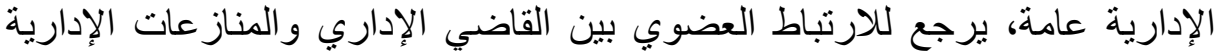

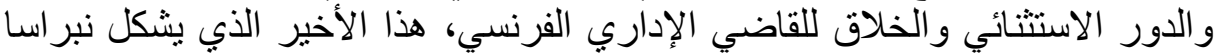

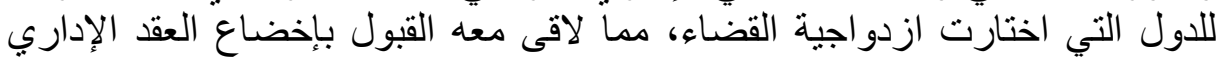

للاتفاق التحكيمي صعوبة كبيرة (12).

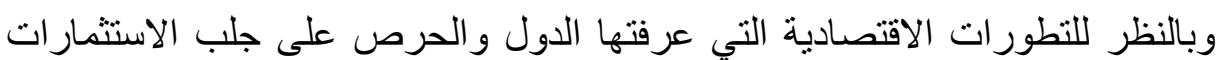

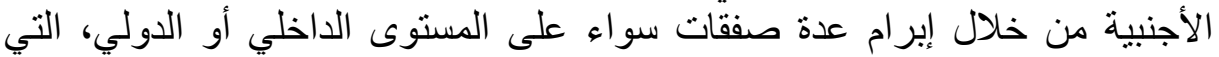

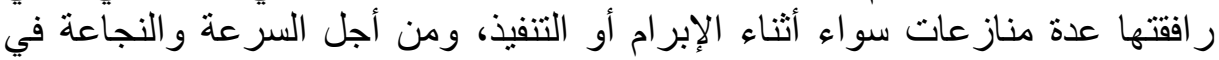

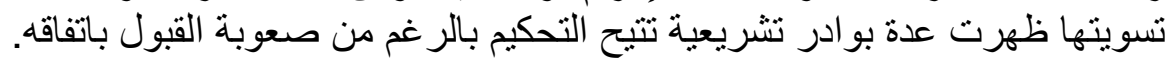

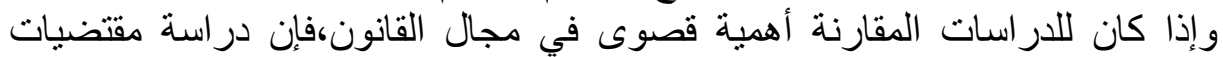

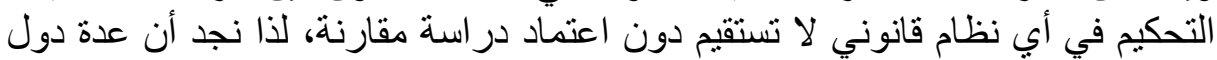
اعتمدت على التحكيم كآلية لجذب الاستثمار ات الأجنبية، و وعملت على سن سن نشريعات وطنية أو تعديلها بغية تحقيق هذه النية الغاية.

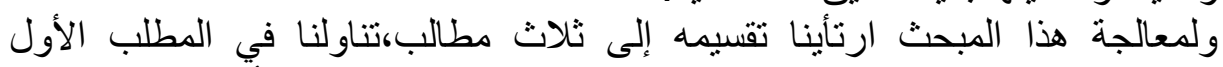

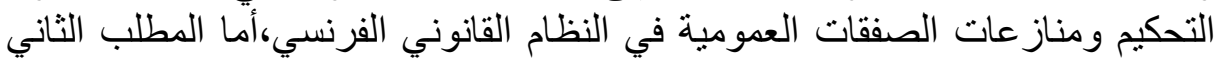

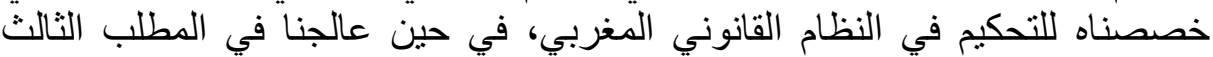
التحكيم في النظام القانوني المصري.

\section{المطلب الأول: التحكيم ومنازعات الصفقات العمومية في النظام القانوني الفرنسي}

لقد نصت المادة 128 من قانون الصفقات العمومية الفرنسي الصادر بموجب القرار 975/2006 ، الصادر بتاريخ 01 أوت 2006 (13) المعدل والمتهم بموجب قانون 01 جانفي 2016 على مايلي: ا وفقا للمادة 69 من قانون 17 أفريل 1906 الذي حدد الميزانية العامة للنفقات والإيرادات لسنة 1906، الدولة، الجماعات المحلية و المؤسسات العمومية

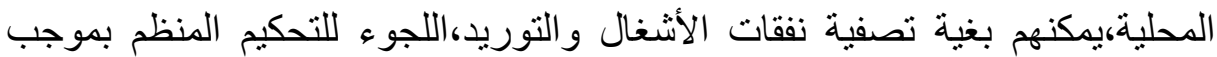
الكتاب IV من قانون الإجر اءات المدنية. بالنسبة للاولة، هذا الطعن يسمح به بموجب مرسوم يؤخذ بناءا على تقرير من الوزير

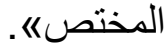
article 128 du code des marchés publics français de 
2006: «conforment à l'article 69 de la loi du 1906 portant fis cation du budget générale des dépenses et des recettes de l'exercice 1906, l'état, des collectivités territoriales ou les établissement publics locaux peuvent pour la liquidation de leurs dépenses de travaux et de fournitures, recourir à l'arbitrage tel qu'il est réglé par le livre IV du code de procédure civile pour l'état, ce recours est autorisé par un décret pris sur le rapport du ministre compétent et du ministre de l'économie».

$$
\text { و عليه سنقوم بتقسيم هذا المطلب إلى الفر عين التاليين: }
$$

الفرع الأول: مبدأ حظر اللجوء للتحكيم لتسوية منازعات الصفقات العمومية.

$$
\text { أولا: موقف المشرع الفرنسي }
$$

يجد الحظر سنده في أحكام المادة 2060 من القانون الددني الفرنسي رقم 626/72

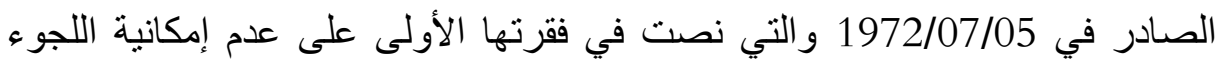

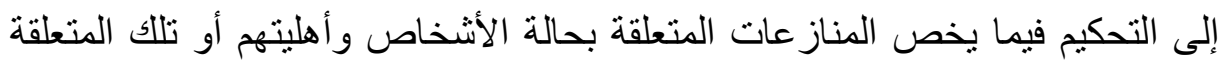

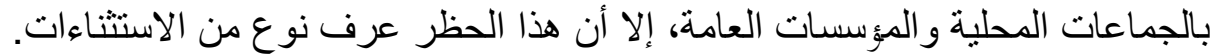
وتجدر الإثارة في هذا المقام إلى أن الحظر يتعلق بمجال القانون العام الداخلي دون الإن العاء

\section{ثانيا: موقف القضاء الفرنسي}

لقد تمسك القضاء العادي الفرنسي بمقتضيات المادة 2060 من القانون المدني، فقضى

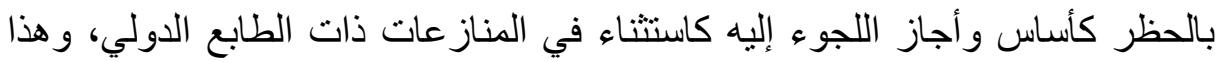

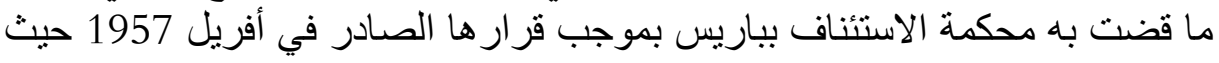
جاء فيه:ا إن التحكيم محظور بموجب قانون الإجراءات المدنية ويتعلق الأمر بالتحكيم

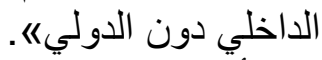

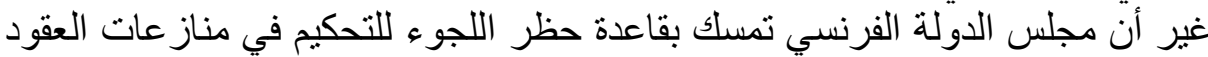
الإدارية وجعل شرط التحكيم فيها باطلا و اعتبر هذا البطلان من النظام العام(15).

الفرع الثاني: إمكانية اللجوء للتحكيم لتسوية منازعات الصفقات العمومية

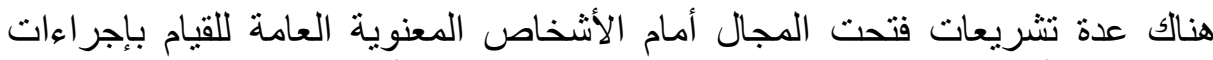

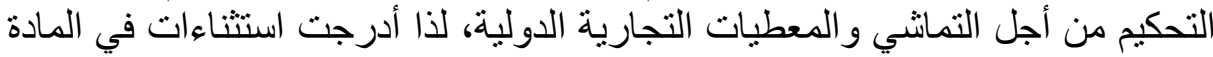
6311 من القانون رقم 388-2000 الصادر في 4 ماي التماي 2000 (قانون العدالة

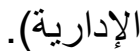
ولقد ثار خلاف بين الفقه والقضاء حول مدى جواز اللجوء إلى التحكيم في العقود

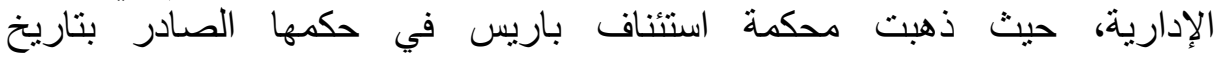

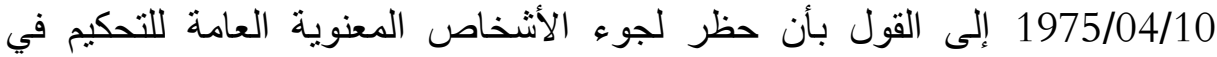

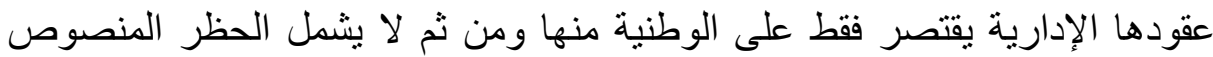

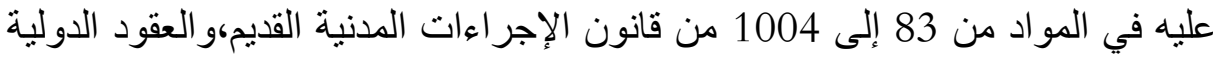


بالمعنى العام سو اء كانت إدارية أو مدنية(16).

لكن بعد صدور قانون 962-972 المؤرخ في 19 أوت 1986 و المتضدنمن أحكام مختلفة

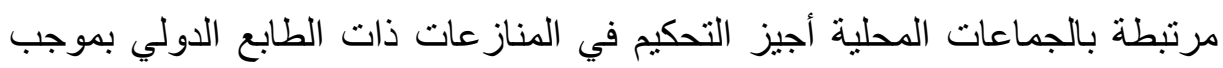
المادة التاسعة منه(17)، حيث جاء فيها مايلي: ال بموجب العات الاستثناء من المادة 2060

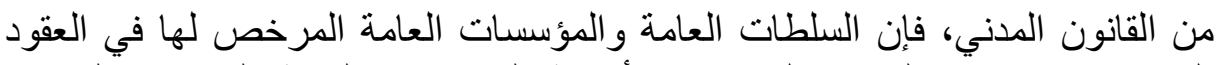

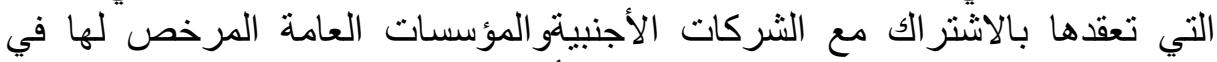

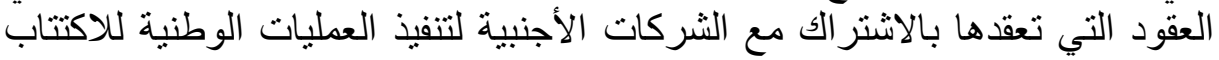

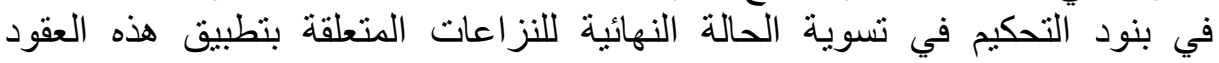
وتغيير هاها.

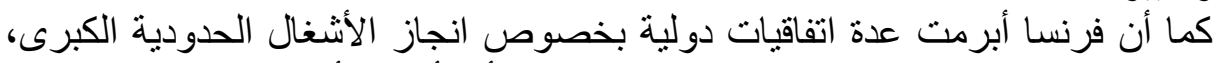

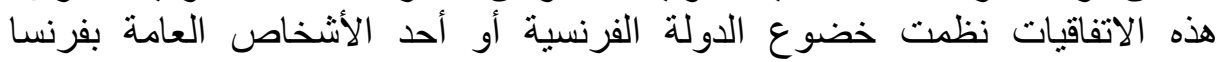

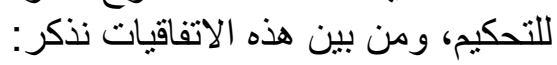
*المادة 16 و 17 من الاتفاقية الفرنسية الايطالية بتاريخ لأفر: 1953/03/14 لانجاز نفق

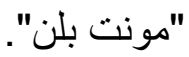

*المادة 19 من معاهدة كناتو زبيري بتاريخ 1986/02/12 المتعلقة ببناء و استغلال

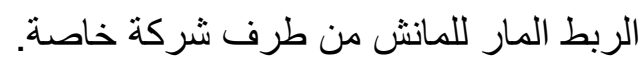

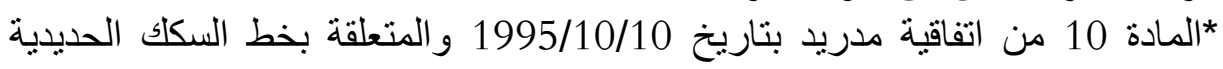
السريع الر ابط بين فرنسا و اسبانيا.

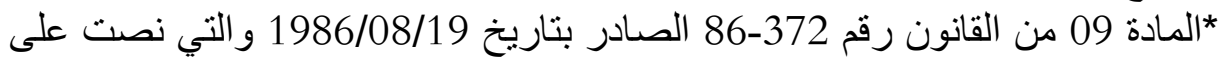

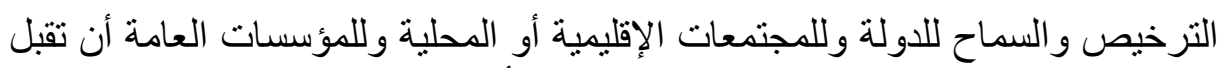
التحكيم في العقود الدولية المبرمة مع شركات أجنبية لتنفيذ عمليات ذات ذات مصلحة الإنة وطنية أو قومية. أيضا القانون الصادر بتاريخ 12 جويلية 1999 والدي أجاز للمؤسسات العلمية

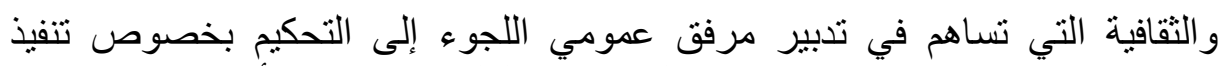
العقود التي تبرمها هذه الَمؤسسات مع تلاير المؤسسات العلمية و الثقافية الأجنيبة.

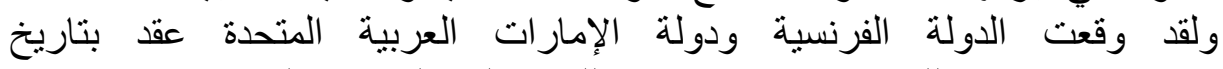

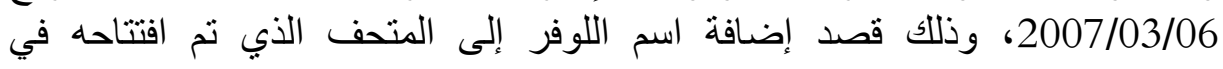

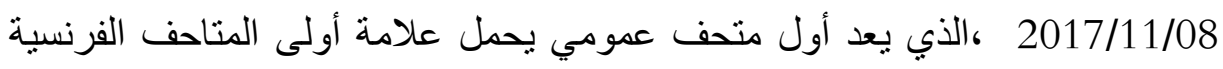

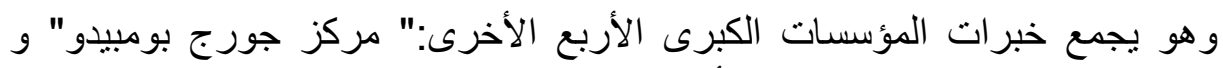

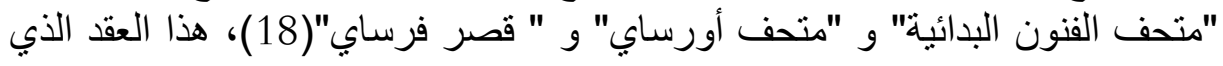

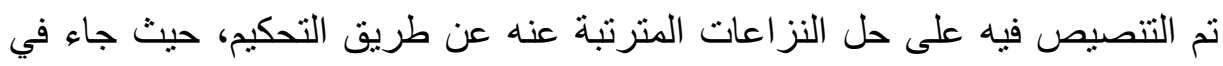

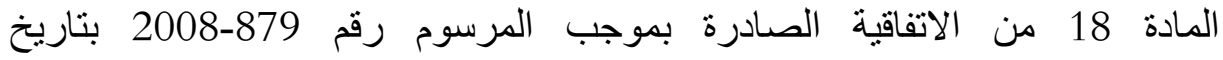
2008/09/01 (19) مايلي: الالنزاعات بين الوكالة ودولة الإمارات العربية المتحدة فيما يتعلق بأداء الوكالة للمدفوعات بسبب تطبيق أو تفسير الاتفاقية الخاصة المشار إليها في المادة 02 من هذا لإنا

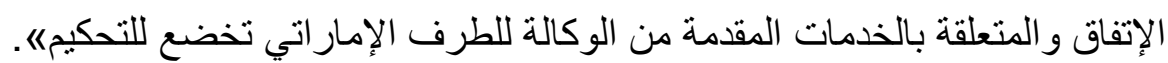

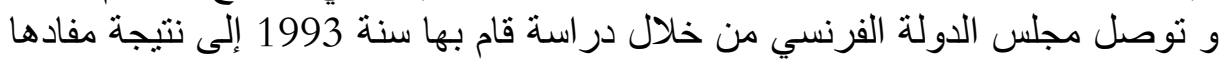
أنه من بين العقود الإدارية نجد أن الصفقات العمومية هي الأكثر استعدادا للتحكيم 
و عليه تم اقتر اح إمكانية التحكيم في جميع الصفقات العمومية لكل الأشخاص المعنوية

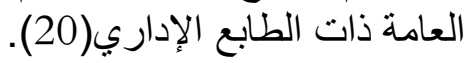
لكن هذه الاقتراحات لم تلقى المتابعة إذ نجد أن اللجوء للتحكيم في مجال الصفار الصفقات العمومية في فرنسا ماز ال جد هامشي (21).

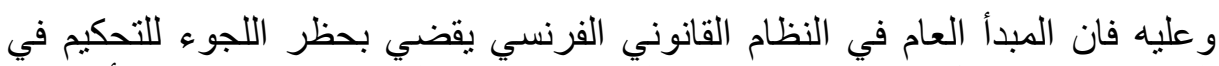

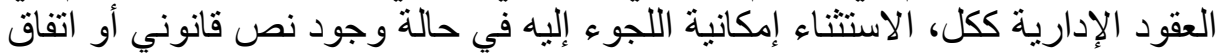

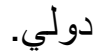

المطلب الثاني: التحكيم ومنازعات الصفقات العمومية في النظام القانوني المغربي

شكل قانون التحكيم رقم 05-08 تطور ا مهما للتحكيم في المادة الإدارية بصفة عامة وفي العقود الإدارية بصفة خاصة، فبعد أن كان الفصل 306 من قانون المسطرة

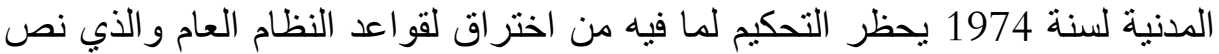

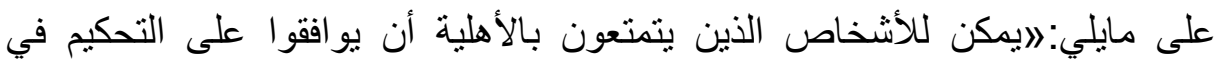
الحقوق الذي يملكون التصرف لإن فيها غير أنه لا بمكن الاتفاق عليه في:

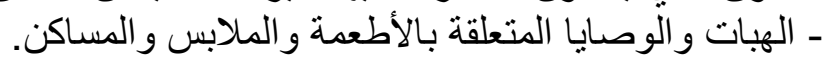
- - في المسائل المتعلقة بحالة الأشخاص النعة و أهليتهم.

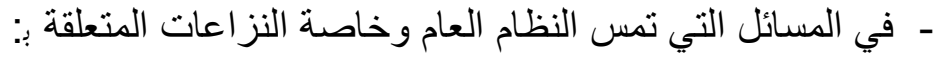
ـ ـ عقود و أمو ال خاضعة لنظام يحكمه القانون العام.

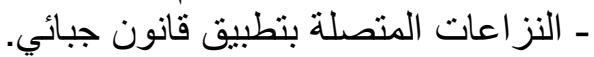

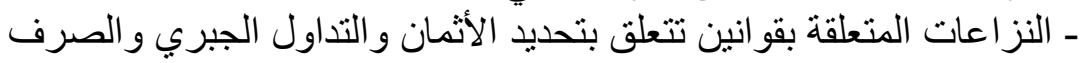

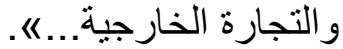
ولقد جاء الفصل 310 من القانون رقم 05-08 السالف الذكر بمقتضيات جديدة قلصت مفهوم نطاق النظام العام في القانون المغربي ووسعت نطاق التهن التحكيم في المادة الإدارية لتصل به إلى حدود قضاء المشام المشروعية (22).

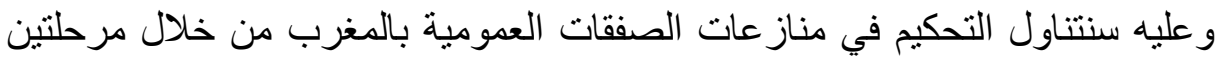

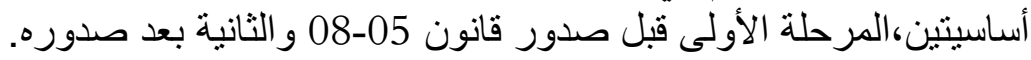
ولقد ارتأينا تقسيم هذا المطلب إلى الفرعين التاليين : الفرع الأول: عدم إمكانية اللجوء للتحكيم ( قبل صدور قانون 05-08 المعدل لقانون المسطرة المدنية). - (الاون.

جاء في الفصول من 527 إلى 549 من قانون المسطرة المدنية المغربي الملغى الصادر بثأنه ظهير 12 أوت 1913على التحكيم في المواد المدنية والتجارية دون الإدارية، و بصدور قانون المسطرة المدنية الحالي في 1974/09/28 نص هو الآخر على التحكيم في الفصول من306الى327 دون التعرض لإمكانية اللجوء إلى التحكيم في مناز عات العقود الإدارية. وبما أن الصفقات العمومية في المغرب تندرجة ضمن العقود الإدارية وتتصب على 
أموال عمومية فلقد جاء في المادة الثانية من مرسوم رقم 2.12 .349 الصادر

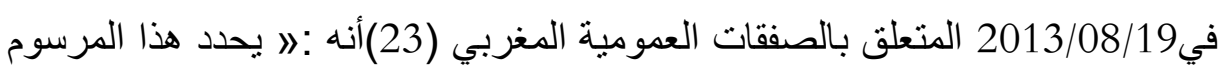

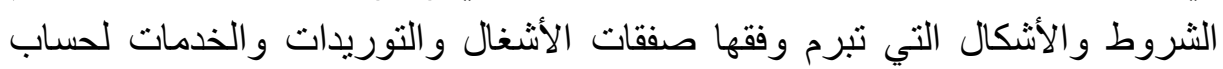

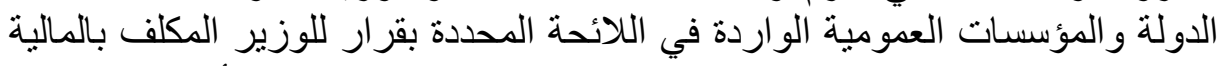

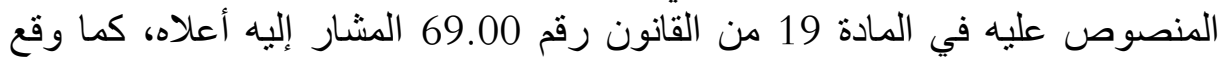

تغييره وتتمبيه .

ويحدد هذا المرسوم كذلك بعض القو اعد المتعلقة بتدبير هذه الصفقات ومر اقبتها .

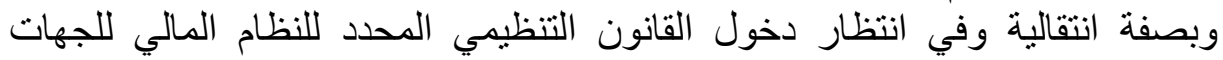
و الجماعات الترابية الأخرى المنصوص عليه في الفصل 146 من النهان الدستور

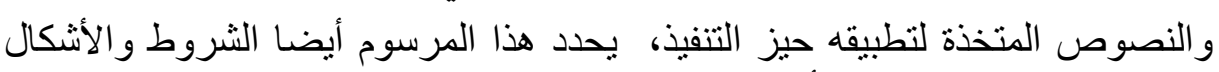

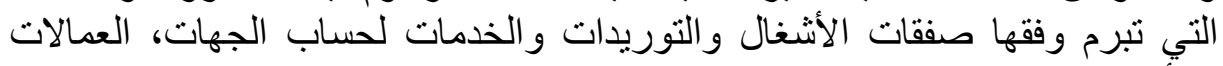

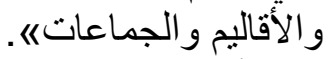

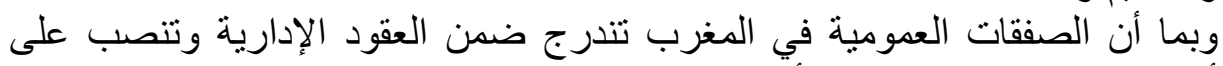

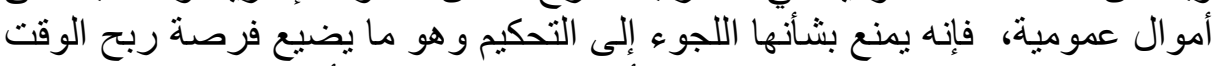

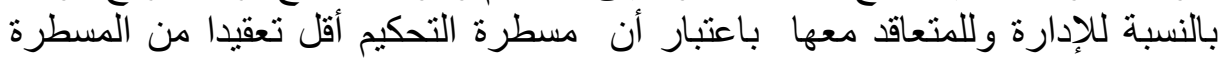

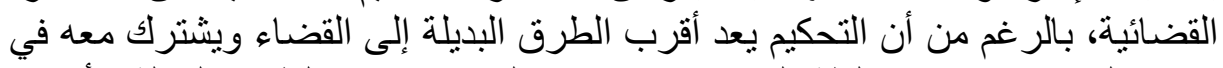

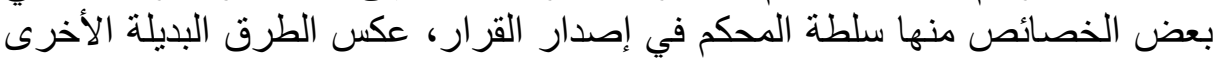

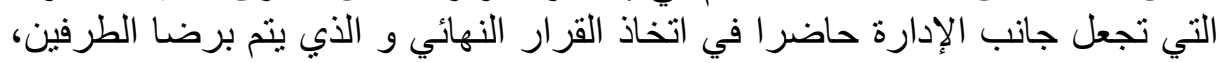

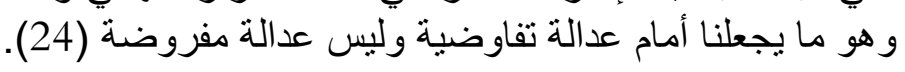
و انطلاقا من أحكام المادة 306 نلاحظ أن المشرع المغربي قد أخذ بأل بالمعيار المادي

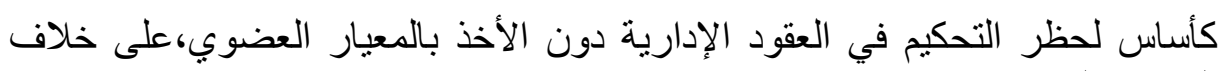
بمعنى أن المشرع المني. المغربي قد حافظ على نفس المنهج الذي تبناه بموجب ظهير 12 أوت1913.

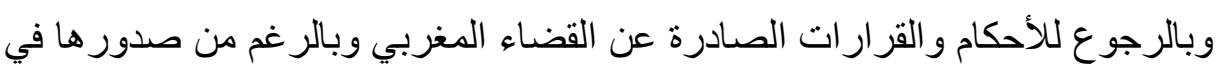

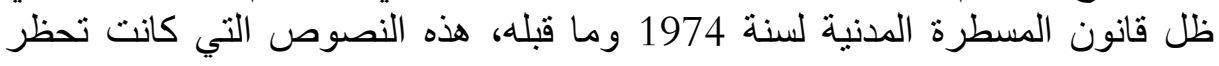

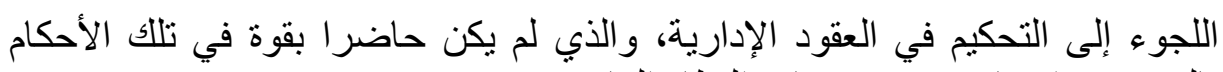

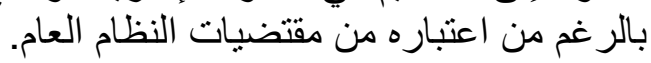
نذكر على سبيل المثال الحكم الصادر عن المن المحكمة الإدارية بأكادير في 2005/11/24

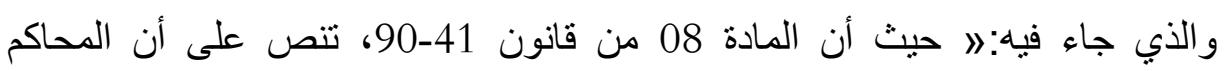

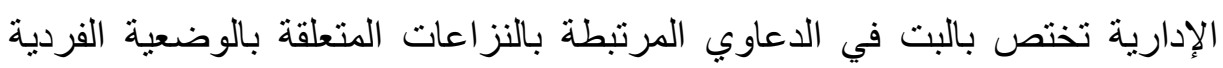

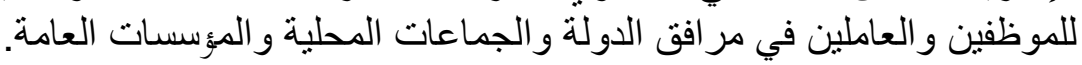

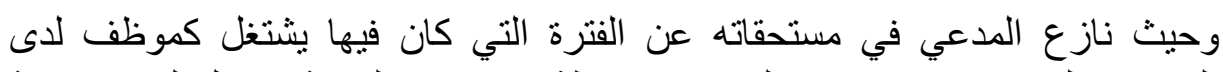

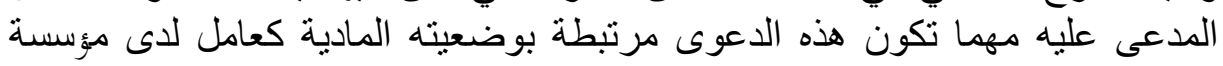

وحيث سبق للطرفين أن اتفقا بموجب الاتفاقية المؤرخة في 2002/07/01 على أن

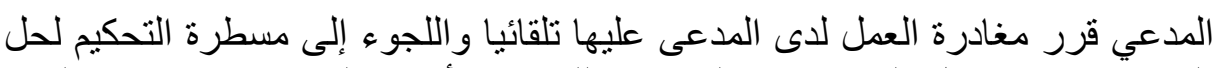

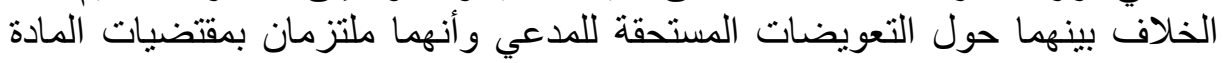
319 وما يليها من قانون المسطرة المدنية. 
حيث أنهما استصدرا الحكم التحكيميالمؤرخ في 2002/07/11 القاضي بمنح تعويض ألمال

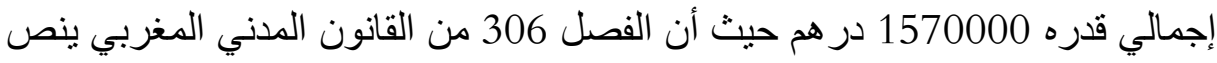

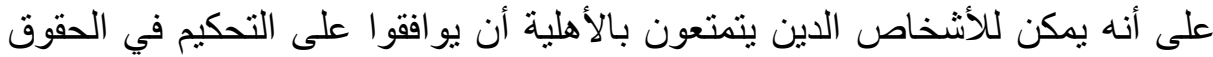

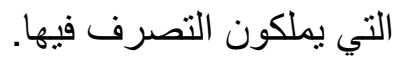
حيث أن نفس المادة لم تسنتن إمكانية التحكيم فيما يخص مستحقات أي موظف بموجب فسخ عقد عمل لدى مؤسسة عمومية. حيث أن الفصل 319 من القانون المدني المغربي ينص على على أنه لا يقبل حكم المحكمين الطعن في أي حالة...«(25).

\section{الفرع الثاني: إمكانية اللجوء للتحكيم في منازعات الصفقات العمومية}

بموجب قانون رقم 05-08 الصادر سنة 2007 و المعدل للقانون المدني السالف الذكر

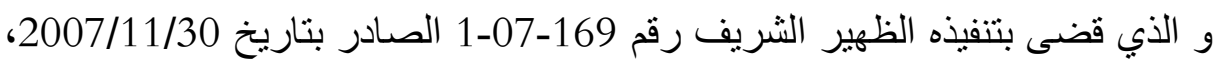
تم النص على التحكيم الاختياري وذللك على الصعيدين الداخلي و الخارجي.

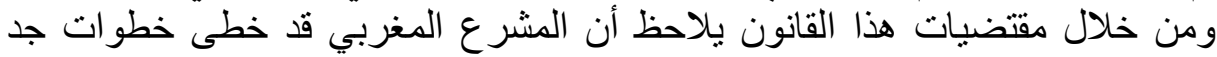
إيجابية في إقرار التحكيم في مجال العقود الإدارية والتي تحتوي بين طياتهاتيات عقود صفقات الدولة(26). فقانون 05-08 لسنة 2007 ومن خلال الفصول 308، 310 و 311، نص المشرع المغربي على إمكانية اللجوء إلى التحكيم في منازعات صفقات الدولة بشروط وضو ابط محددة. فالفصل 308 جاء فيه: اليجوز لجميع الأشخاص من ذوي الأهلية الكاملة سواء أكانوا

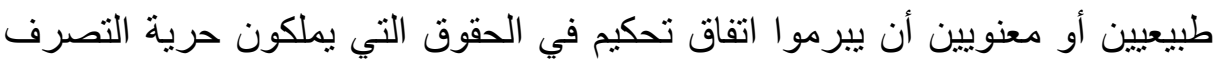

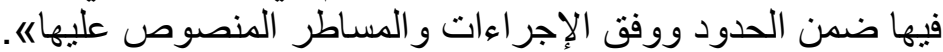
كما نص الفصل 310 فقرة 03 على أنه: الايمكن أن تكون النزاعات المتعلقة بالنقالعقود التي تبرمها الدولة أو الجماعات المحلية محل اتفاق تحكيم....

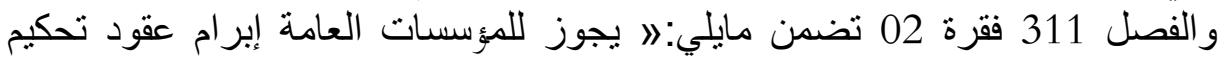
وفق الإجر اءات و الثروط المحددة من لان مجالس إدارتها وتكون الاتفاقيات المتضمنة

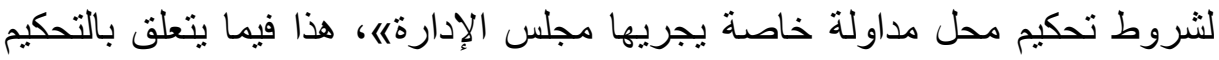

أما التحكيم الدولي في مادة الصفقات العمومية فلقد نصت عليه إلى جانب القوانين الداخلية اتفاقيات دولية تمت المصادقة عليها من طرف المغرب ونذكر على سبيل

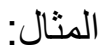
القانون الإطار رقم95-18 لسنة 1995 و الذي يعد بمثابة ميثاق الاستثمار(27) و الذي نص في مادته 17 على إقرار مبدأ التحكيم في النزاعات القائمة بين الدولة المغربية الدابية و والمستثمر الأجنبي في العقود الإدارية الدولية. وفيما يخص الاتفاقيات الدولية نذكر :

1- اتفاقية التبادل الحر بين المملكة المغربية ولئ الو لايات المتحدة وتسوية المناز عات 
المتعلقة بها عن طريق التحكيم و الوساطة بتاريخ 02 مارس2004.

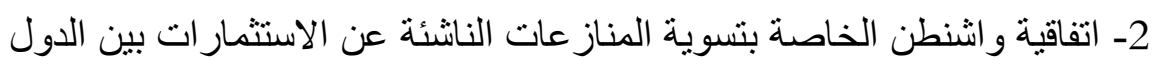

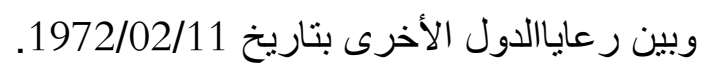

3- اتفاقية نيويورك بثأن الاعتر اف وتنفيذ أحكام المحكمين الأجنبية بتاريخ 10 يونيو 1958 و التيتعد من المرجعيات الأساسية في التحكيم.

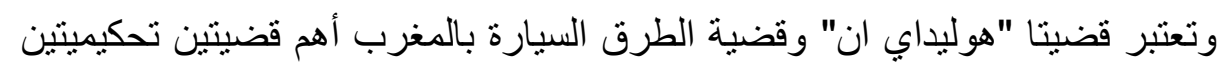

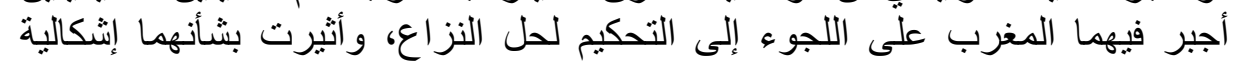

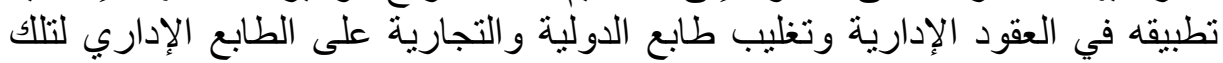
العقود.

ففي القضية الأولى: بعد أن أخلت شركة "هوليداي ان" والشركة الغربية للبترول

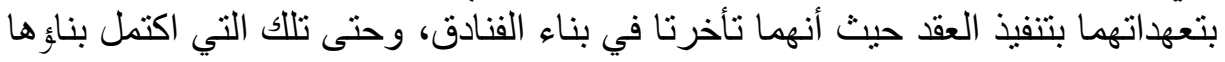

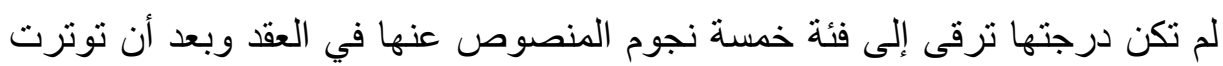

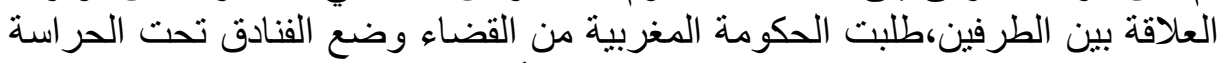

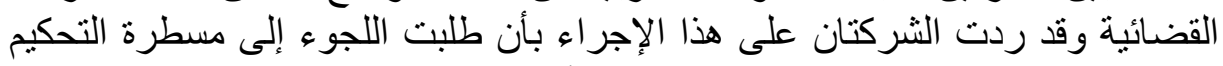

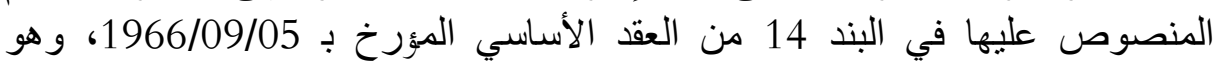

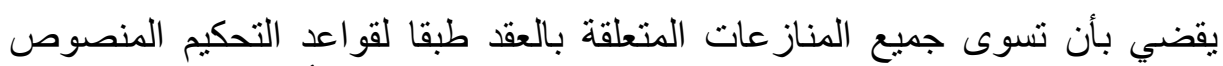

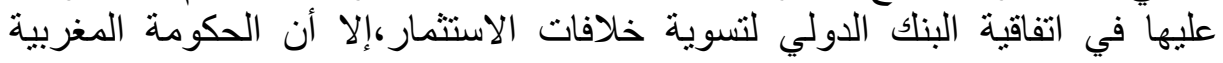

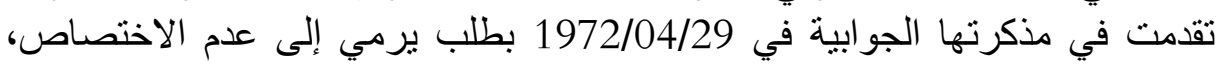

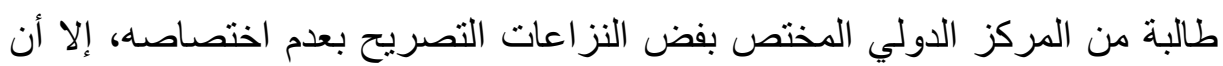

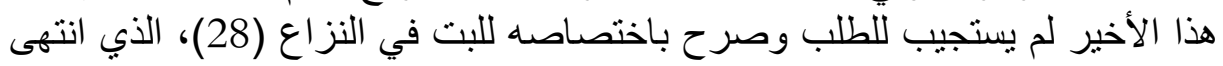

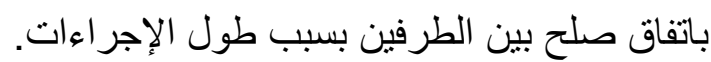

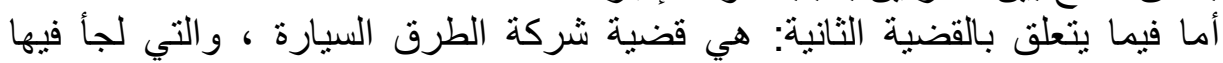

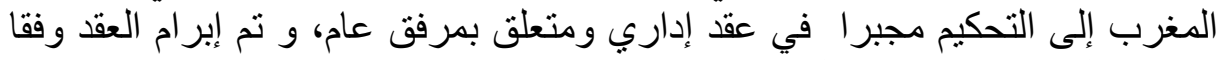

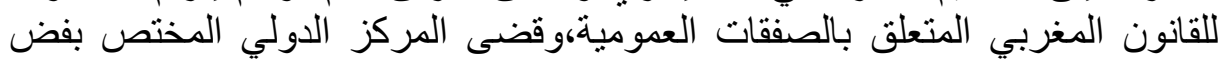

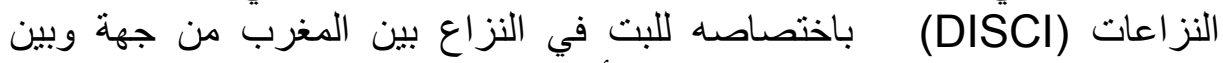

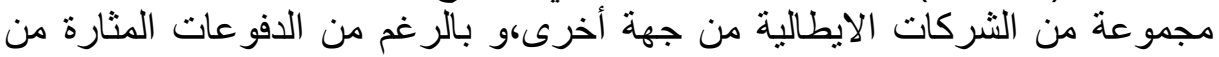

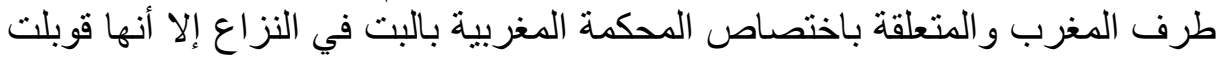
بالرفض من طرف المركز (29).

المطلب الثالث: التحكيم ومنازعات الصفقات العمومية في النظام القانوني المصري لقد ظهرت فكرة التحكيم في مصر في أواخر القرن التاسع عشر، حيث تدخل المشرع

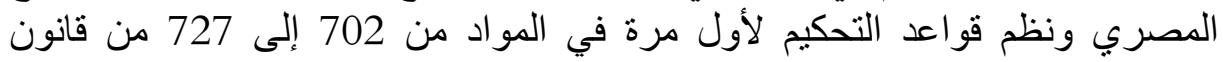

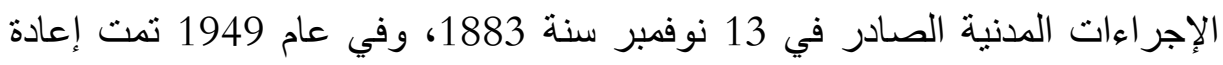
تتظيم التحكيم في المواد من 818 إلى 850 من قانون الإجراءات المداءنية المانية، وأخيرا تم

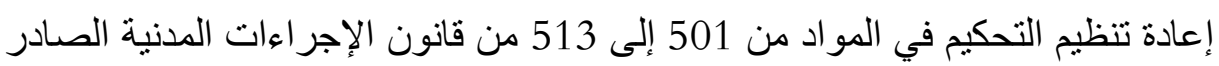
عام 1968. وحتى أواخر القرن العشرين ظل تنظيم التحكيم ضمن نصوص قانون الإجراءات

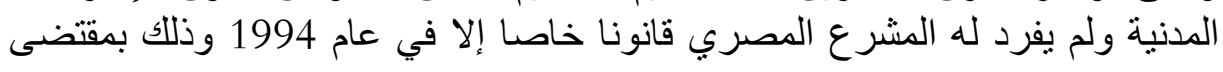


قانون رقم 27 لسنة 1994 الخاص بالتحكيم في المواد المدنية والتجارية المعدل بمقتضى القانون رقم 09 لسنة 1997 (30). ففي الفترة السابقة على صدور قانون التحكيم السالف الذكر، تباينت آراء الفقه و

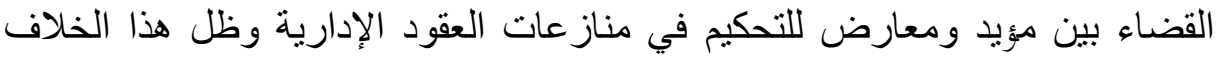

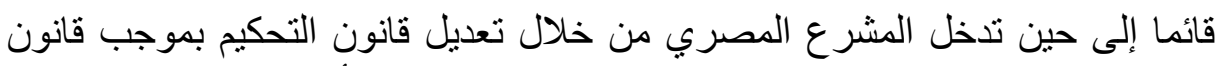

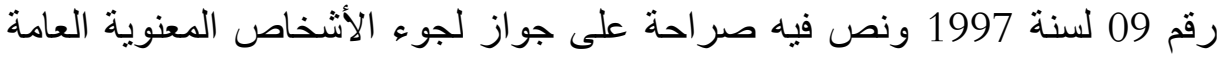

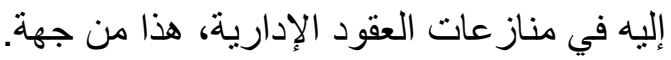

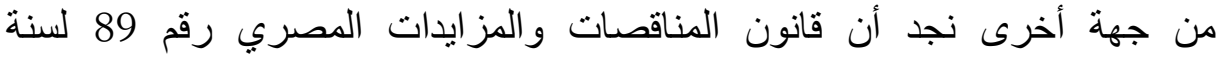
1998(31) نص على آلية التحكيم في المادنين 23 و 42.

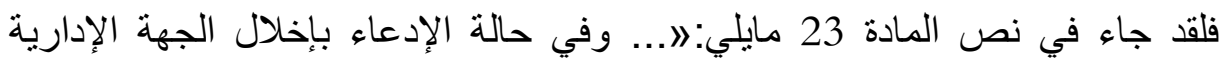

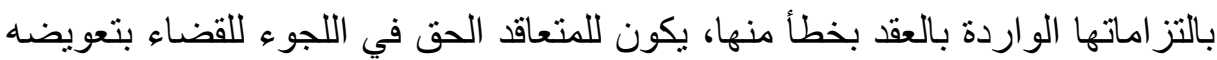

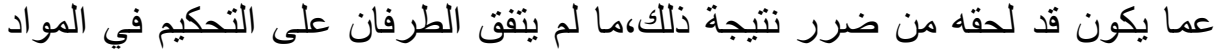
المدنية والتجارية الصادر بالقانون رقم 27 لسنة 1994 معدلا بالقانون 09 لسنة

أما المادة 42 فلقد نصت على ما يلي: ا يجوز لطرفي العقد عند حدوث خلاف أثناء

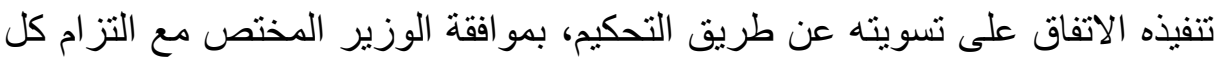

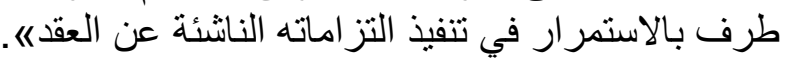

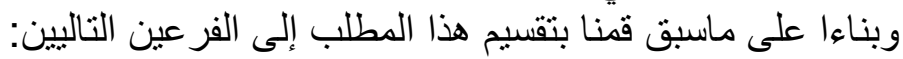

\section{الفرع الأول: التحكيم في الصفقات العمومية على ضوء قانون رقم 27 لسنة 1994}

قبل صدور قانون رقم 27 لسنة 1994 و المتعلق بالتحكيم في المواد المدنية والتجارية، اختلف الفقه والقضاء حول إمكانية تطبيق التحكيم في المنازعات الإدارية بين مؤيد ومعارض ولكل اتجاه من الاتجاهين مبرر اته و أسانيده.

أولا:الموقف المعارض.

1/ موقف التشريع: يرى المعارضون أنه لا يمكن الأخذ بالتحكيم في العقود الإدارية

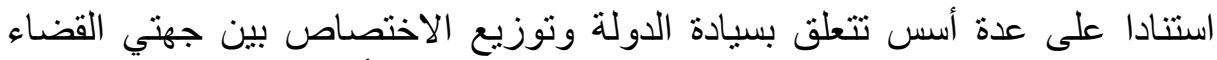

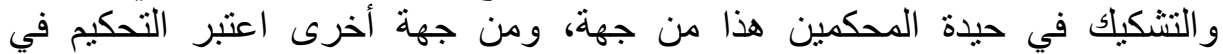

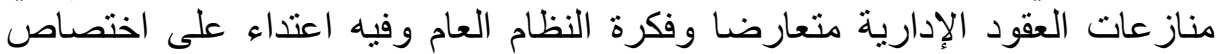

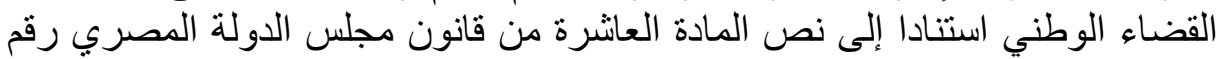

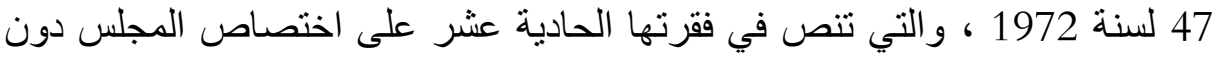

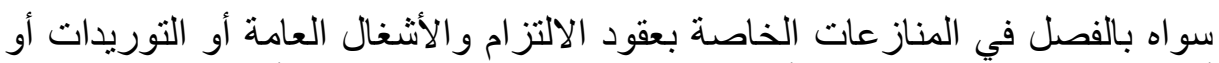

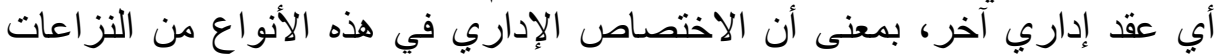

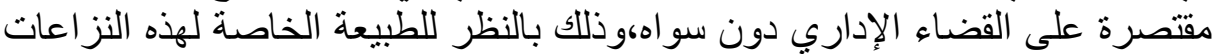

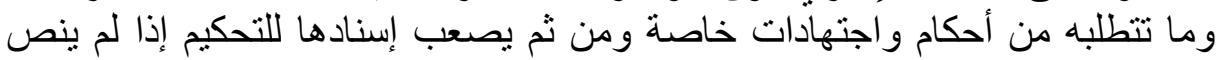

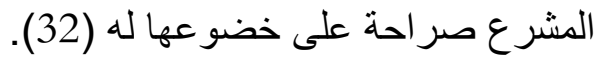
2/ موقف القضاء: نجد أن مجلس الدولة المصري بشقيه الإفتائي والقضائي تباين بين 
الإجازة و الرفض فيما يتعلق بالتحكيم في العقود الإدارية.

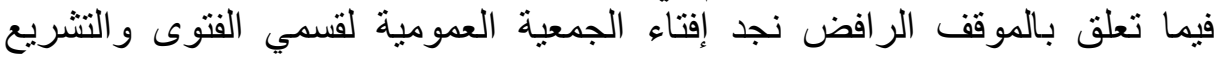

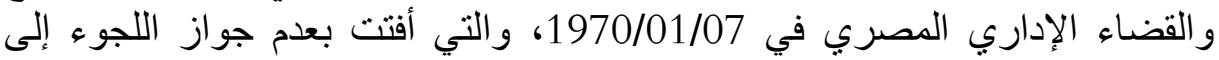

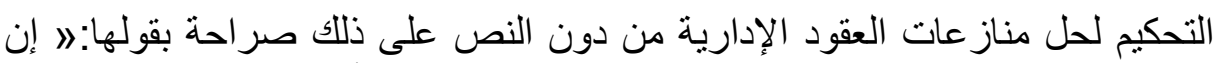

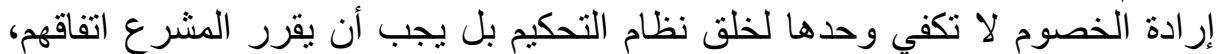

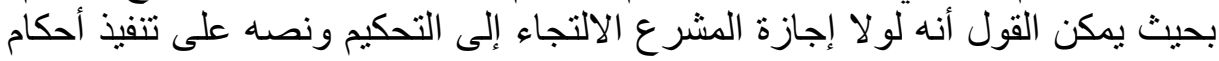

المحكمين ما كانت إر ادة الخصوم وحدها لإنها كافية لخلقهاء (33).

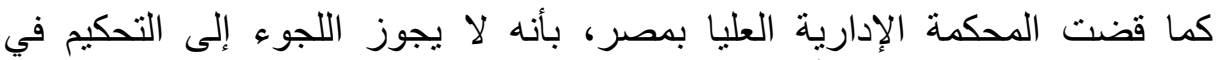

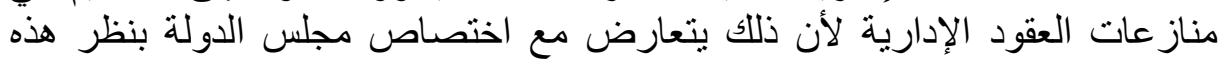
المنازعات وذللك طبقا للمادة العاثرة من قانون مجلس الدولة رقان الانم 47 لسنة

. (34)1972

كما رفضت محكمة القضاء الإداري المصرية التحكيم و اتبعت نفس نهج المحكمة

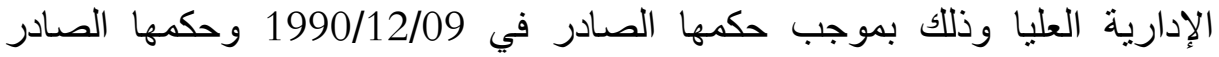
في1991/01/30 وقد صدر هذا الأخير في دعوى تتلخصوقائعها فيمايلي:قامت وزارة ونها

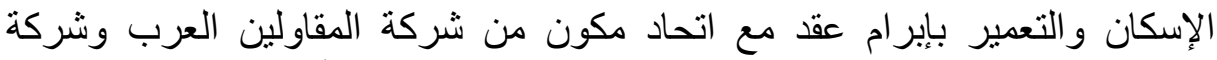
تارماك الانجليزية عبر البحار في 1976/03/01 وذلك من أجل إنشاء نفق الثهير الثيد أحمد حمدي، وتضمن العقد بندا تعهة بمقتضاه الطرفين على إحالة النزاع الذئي الذي يمكن

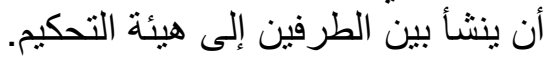

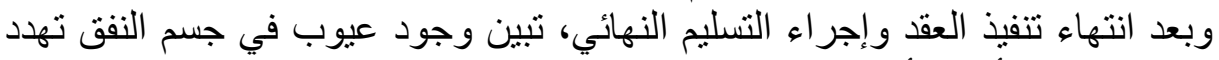
سلامته نتيجة تأثير الأملاح التي تسربت بداء التخله.

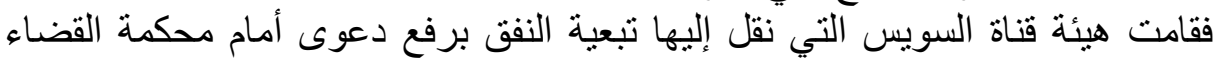

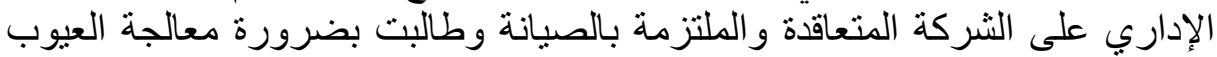

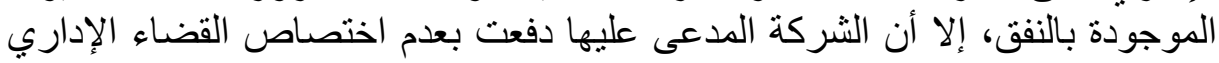

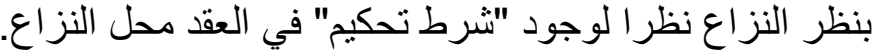

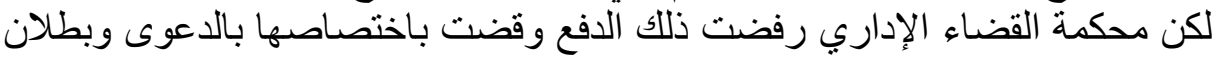

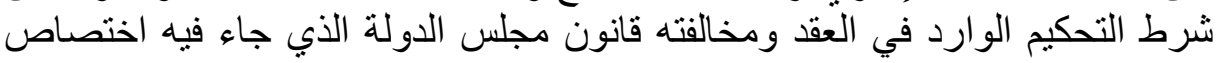

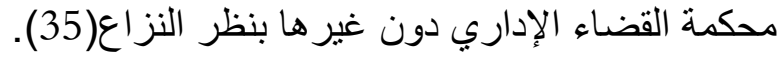

\section{ثانيا : الموقف المؤيد.}

1/ موقف التشريع :يرى المؤيدون أن المشرع لم يقصد من نص المادة 10 من قانون

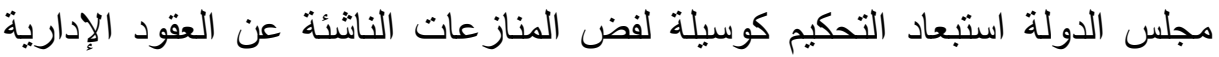

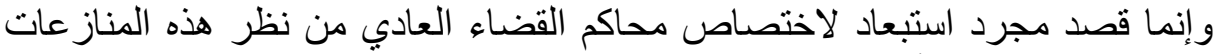

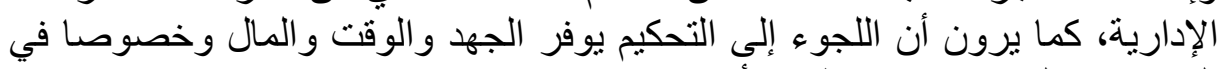

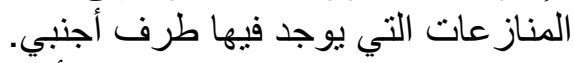

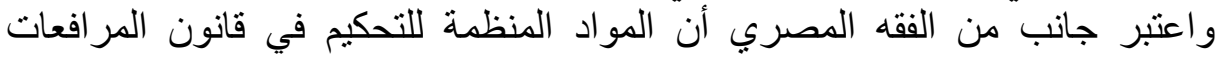

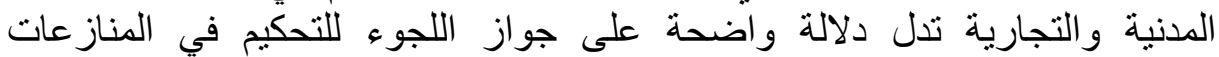

الإدارية(36).

وبعد صدور قانون رقم 27 لسنة 1994 المتعلق بالتحكيم في المواد المدنية والتجارية

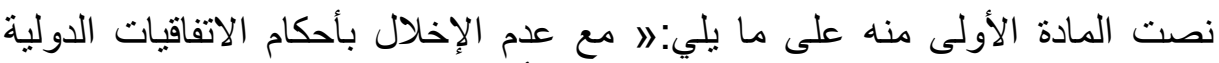

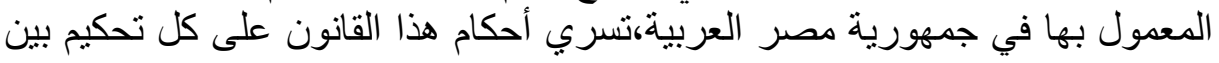


أطر اف و أشخاص القانون العام أو القانون الخاص أيا كانت طبيعة العلاقة القانونية

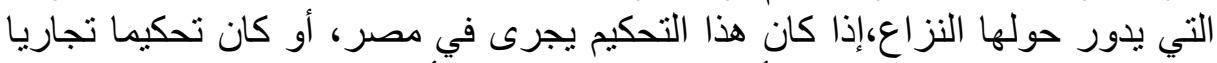

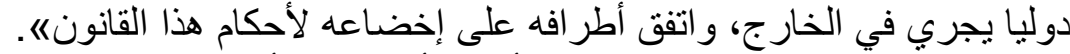

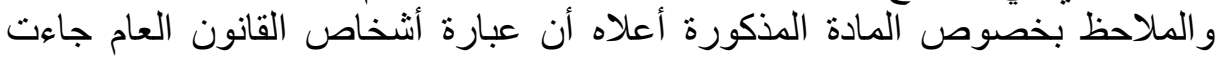

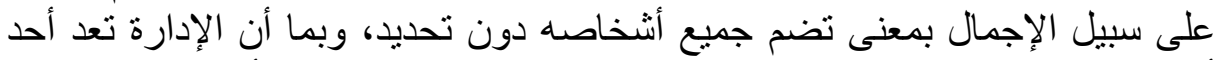

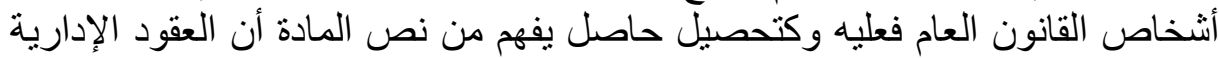

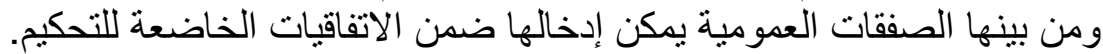

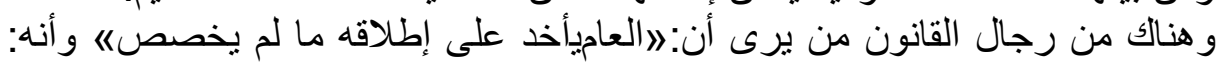

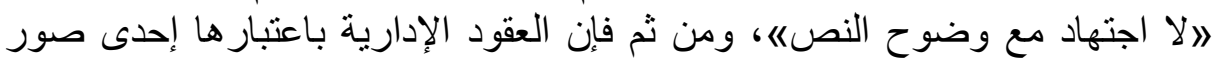

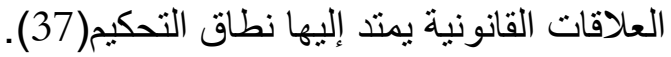

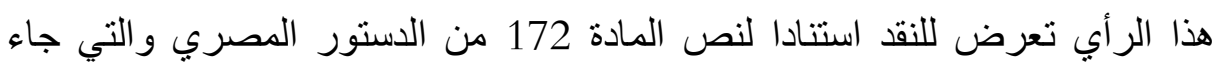

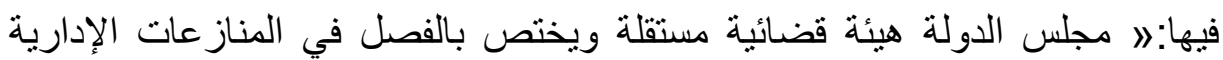
وفي الدعاوي التأديبية ويحدد القانون اختصائة التصاصناته الأخرىها. /2 موقف القضاء: بالرجوع للأحكام القضائية نجد أن حكم المحكمة الإدارية العليا الأيا بمصر الصادر في 2005/05/31 ، فيه اعتر اف ضمني بقبول التحكيم والذي جاء التهاء

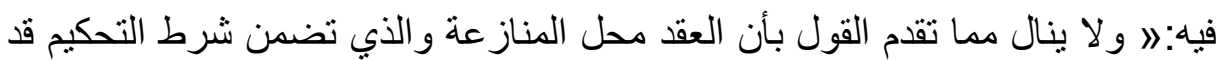

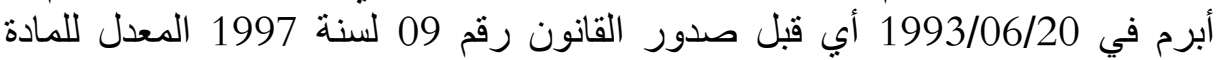
الأولى من قانون التحكيم في المواد المدنية والتجارية الصادر بالقانون رقانم 27 لسنة 1994، فهذا القول مردود بأن قضاء هذه المحكمة جرى قبل تعدئ العديل المادة الأولى سالفة

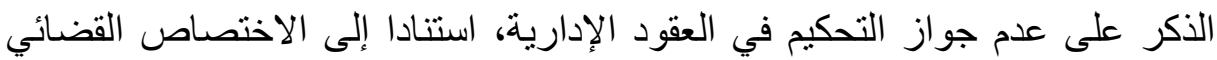

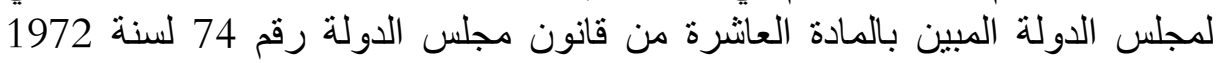

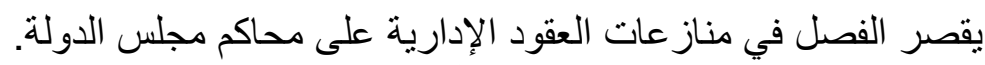

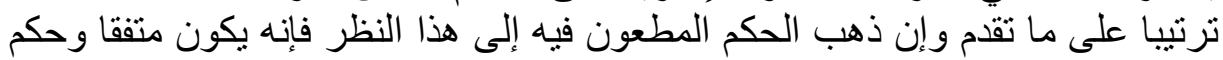

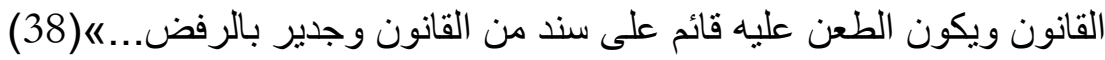

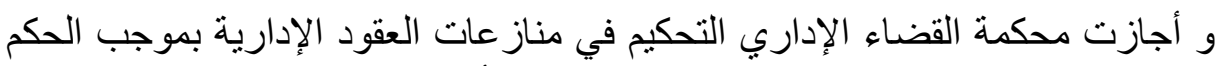

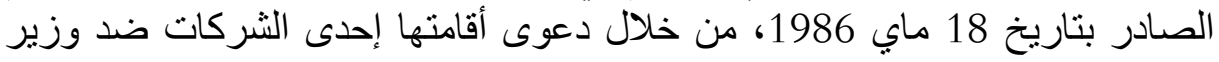

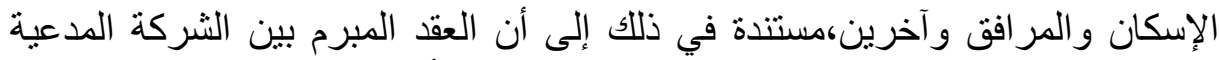

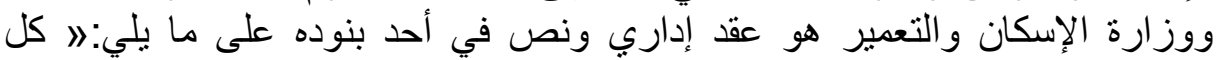

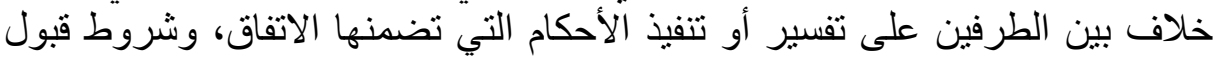

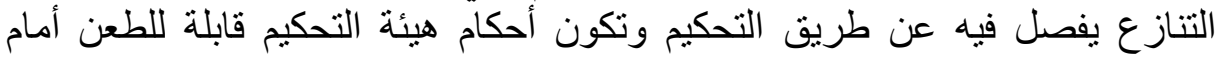

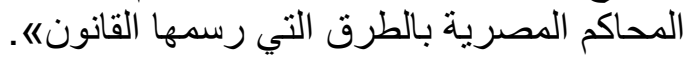

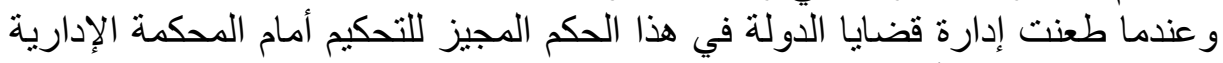
العليا، قضت هذه الأخيرة بإلغائه مقررة عدم جواز التهائ التحكيم في العقود الإدارية(39).

\section{الفرع الثاني: التحكيم في الصفقات العمومية على ضوء قانون رقم 09 لسنة 1997.}

إن قانون رقم 09 لسنة 1997 المعدل لقانون التحكيم في المواد المدنية والتجارية ومن

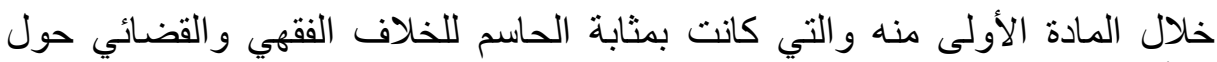

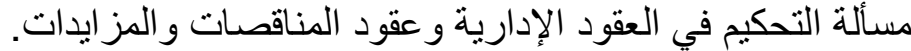
فبالرجوع لنص المادة الأولى من قانون رقدم 17 لسنة 1994 نجد أن هنالك فقرة قد الد 
أضيفت بموجب قانون رقم 09 لسنة 1997 والتي جاء فيها: ا بالنسبة إلى منازعات

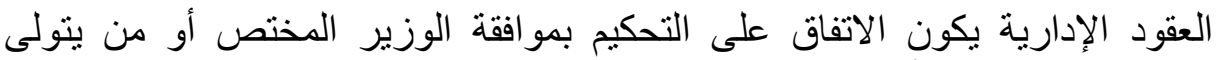

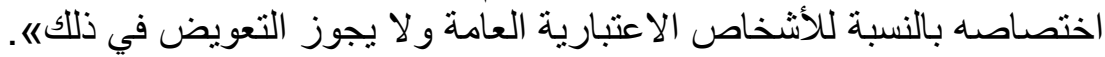

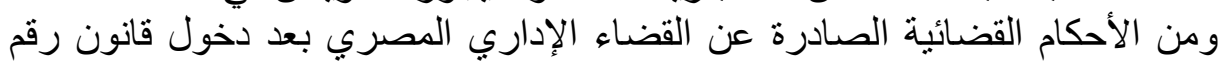
09 لسنة1997 حيز التنفيذ نذكر على سبيل المثال: الحكم الصادر عن محكمة القضاء الإداري بالقاهرة بتاريخ 2006/02/19 و الذي جاء " وحيث أنه يتعين التنويه إلى أن مجلس الدولة الفرنسي ظل رافضا مبدأ التحكيم في والإني

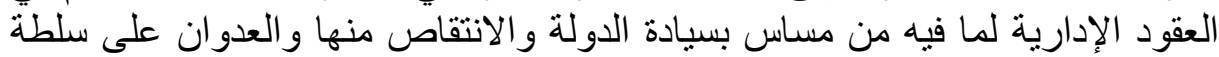

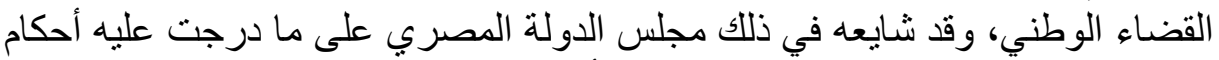

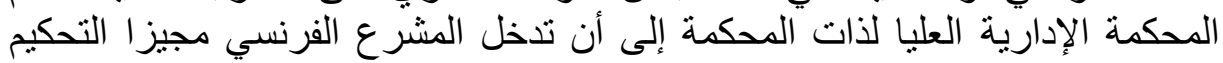

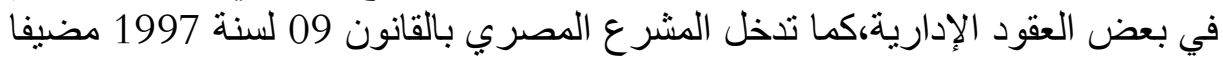

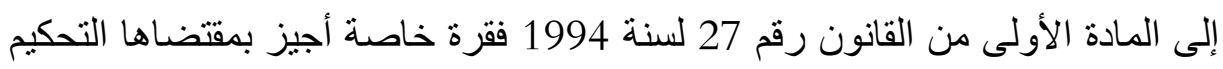

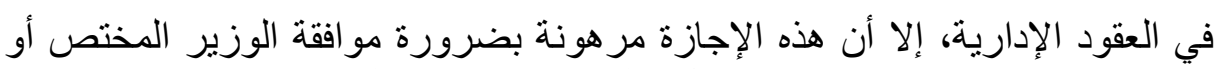

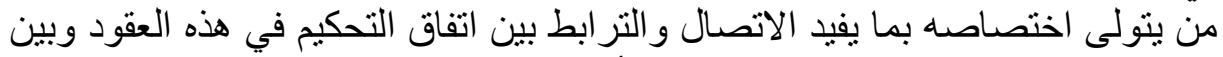

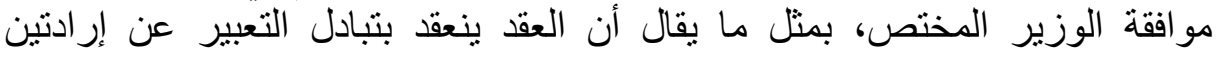

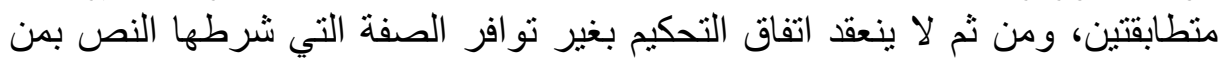

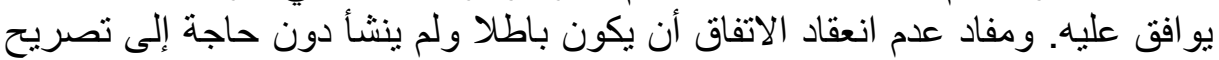
بذلك يرد في ألفاظ النص.

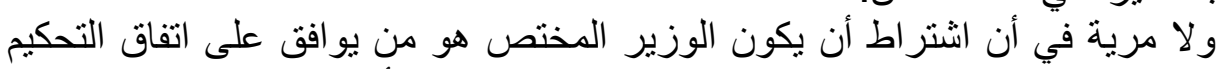

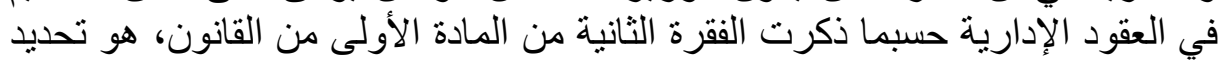

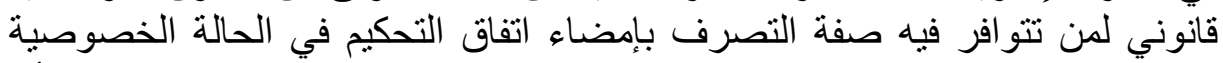

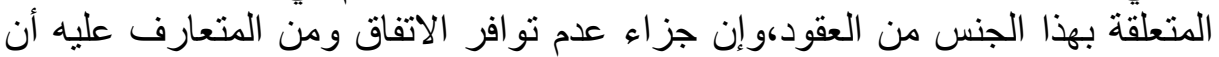

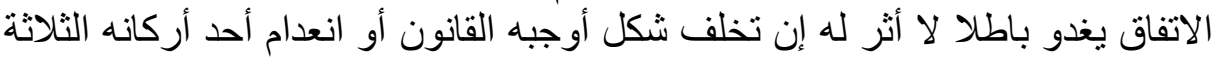

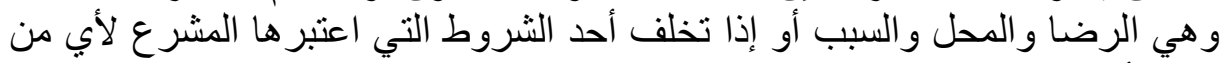
هذه الأركان الثلاثة. ومن ذلك ما أوردنه الفقرة الثانية من المادة الأولى من قانون التحكيم متعلقا بوجوب

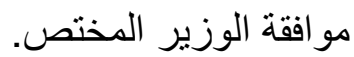

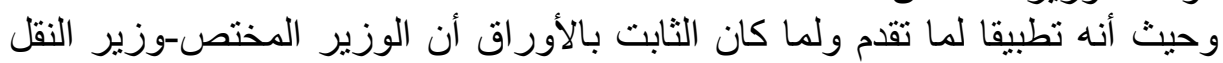

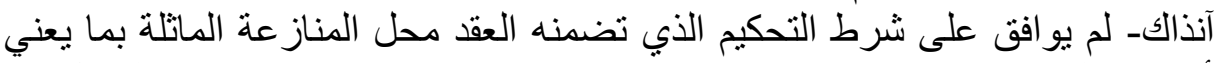

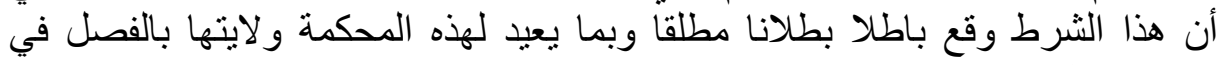

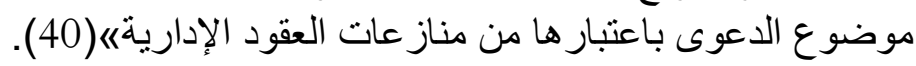

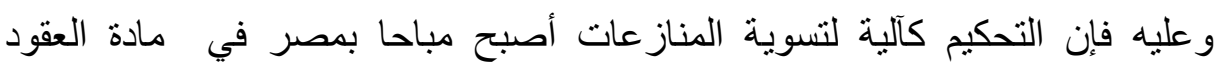

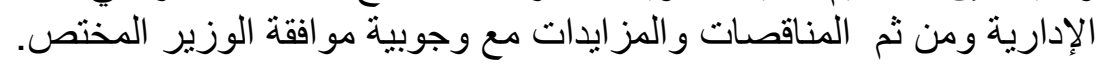


إن التحكيم في الوقت الراهن أصبح مطلبا من منطلبات الدولة الحديثة

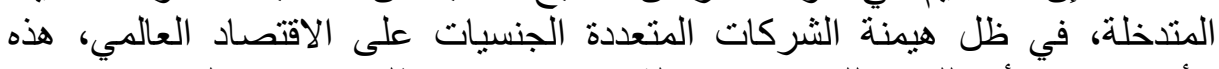

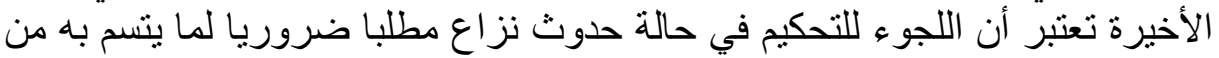

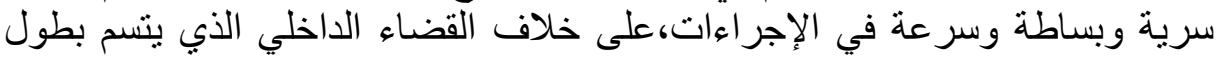

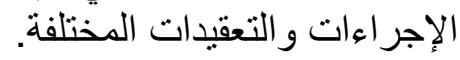

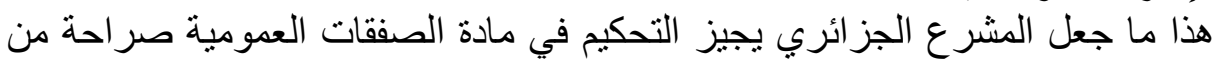
خلال قانون الإجراءات المدنية والإدارية 09/08 حيث نجد أن المادة 976 نصت فئ

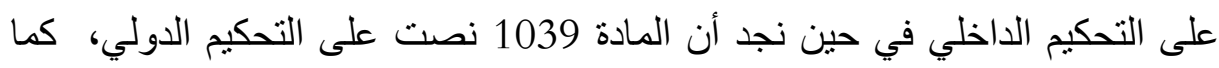
ورد في المادة 153 من المرسوم الرئاسي المتضمن تنظيم الصفقات العمومية وتفويضات المرفق العام رقم 15- 247 خضوع المصلحة المتعاقدة لهيئة تحكيم دولية في حالة النزاعات المتعلقة بتنفيذ صفقات عمومية مبرمة مع متعاتماتملين متعاقدين

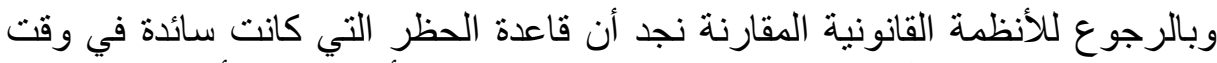

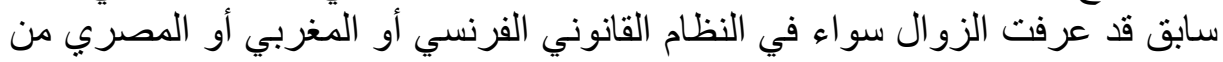

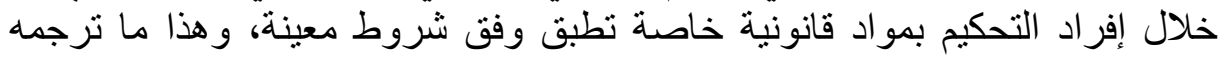

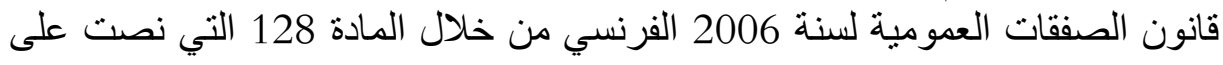

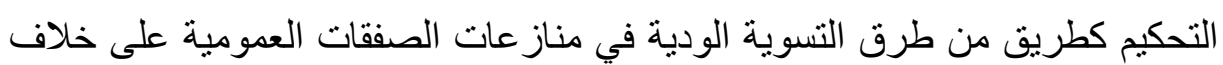

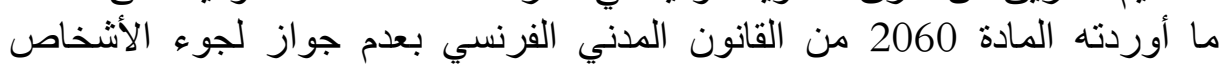

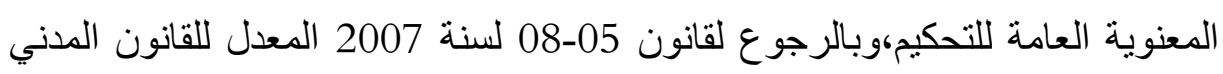

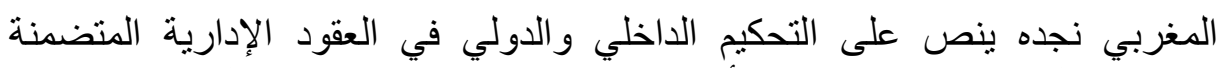

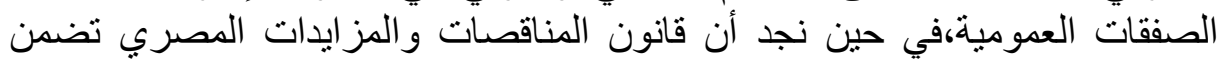

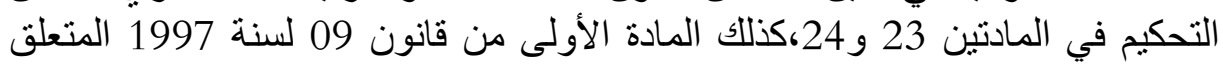
بالتحكيم في المواد المدنية والتجارية التي نصت في على التحكيم الداخلي أما المادة الثانية فلقد نصت على التحكيم الدولي.

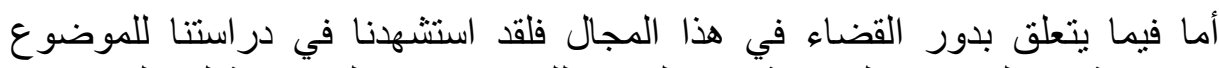

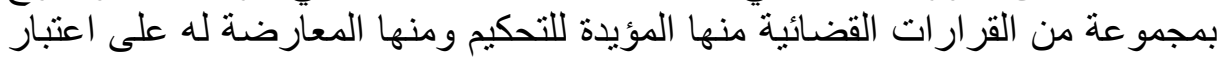

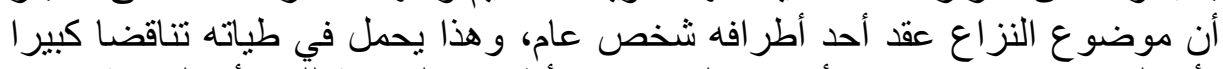

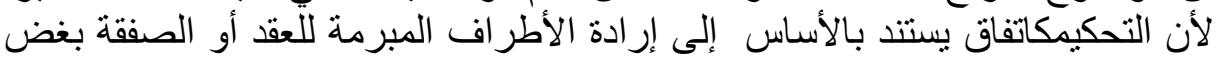

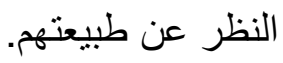




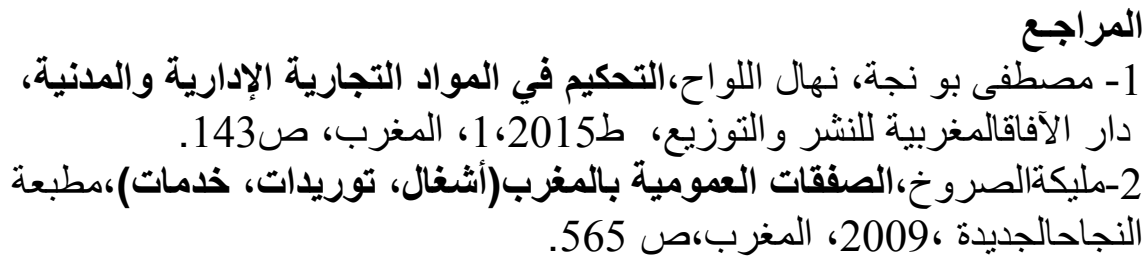

3-mohamedISSAD, le nouveau droit Algérien de l'arbitrage

international, Séminaire de la chambre national du commerce, Alger 14- 15décembre1992, p 2.

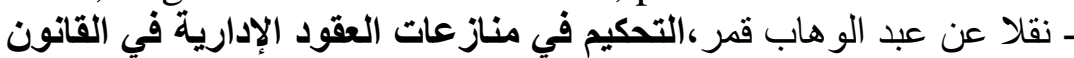

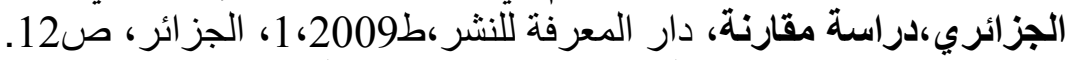

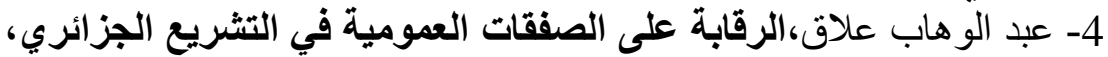

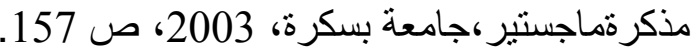

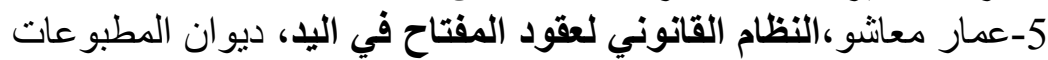

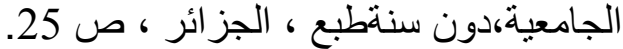

6- Ahmed MAHIOU, l’arbitrage en Algérie, revue Algérienne, nº4,1989, p720.

7ـ لقد نصت الفقرة الأولى من المادة 442 من الأمر 66-154 الملغى على مايلي:

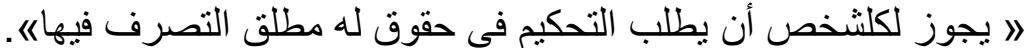

8- Mohamed BEDJAOUI, un tournant remarquable dans la législationalgérienne relative à l'arbitrage commercial international,bulletin de la cour international d'arbitrage de lachambre commercial international C.C.I, vol 4, $\mathrm{n}^{\mathrm{0}} 21$, octobre 1993, p55.

ـ نقلا عن كمال علبوشقربوع ،التحكيم التجاري الدولي في الجزائر،ط3،

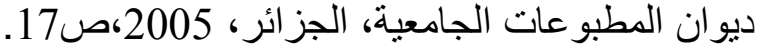

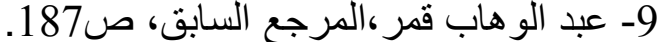

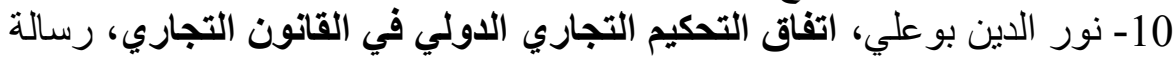

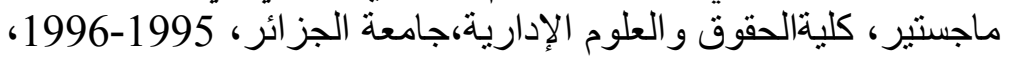

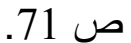
11- عبد الوهاب قمر ، المرجع السابق، ص 11 ص 188.

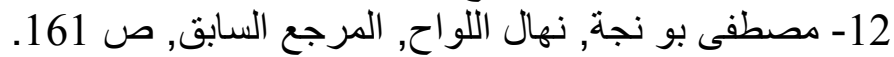
13- منشور بالجريدة الرسمية الفرنسية رقم 179 الصادرة بتاريخ الصناريخ 2006/08/04،

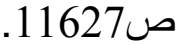

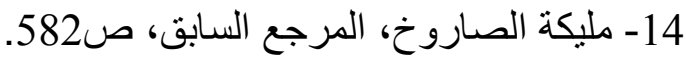

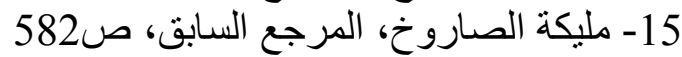

16-cours administrative de paris, le 10/04/1957, société myrtoor steamship contre ministre de la marine marchande.

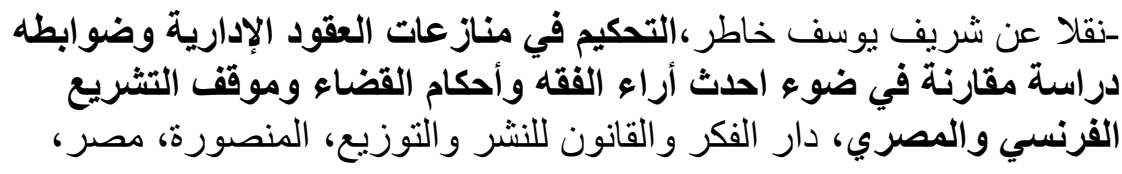

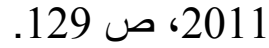


17- article 09 de la loi no86-972 du 19 aout 1986 portant disposition diverses relative aux collectivités locales: « par dérogation à l'article 2060 du code civil, l'état, les collectivitésterritoriales et les établissement publics sontautorisés ; dans les contratsqu'ilsconcluentconjointement avec des sociétésétrangères pour la réalisationd'opérationsd'intérêt national, à souscrire des clauses compromissoires en vue du règlement, les caséchéantdéfinitif de litigesliés à l'application de cescontrats».

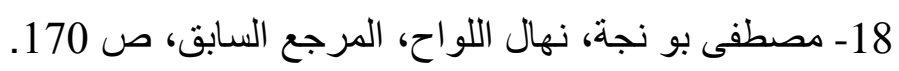

19- Accord publié par le décret n²008-879 du 01/09/2008, article

18 : «Les différents entre l'agence et la Partie émirienne relatifs aux prestations par l'agence aux versements qui lui sont dus, à l'applicabilité ou à l'interprétation de la convention particulière prévue à l'article 02 du présent accord et relative aux services de concret que l'agence fournit à la partie émirienne sont soumis à l'arbitrage».

$$
\text { 20-مثل صفقات تثييد الطريق السيار. }
$$

\section{1- CatherineBERGEL et Frédéric LENICA,Le contentieux}

desmarchés publics, imprimerie national ,Paris,France, p279.

$$
\begin{aligned}
& \text { 22- مصطفى بو نجة، نهال اللواح، في المو اد التجارية الإدارية }
\end{aligned}
$$

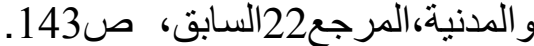

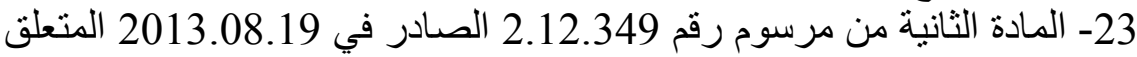

بالصفقات العمومية المغربي،منشور في الجريدة الرسمية المغربية، عدد6182 6132 ، 29.

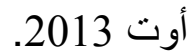

24- عبد المجيد غميجة،الطرق البليلة لتسوية المنازعات، أنثغال الندوة العلمية التي

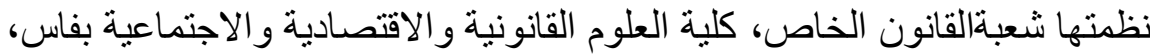

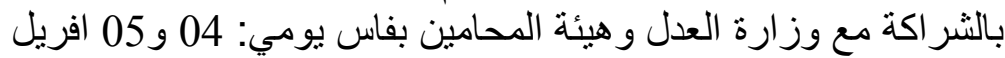

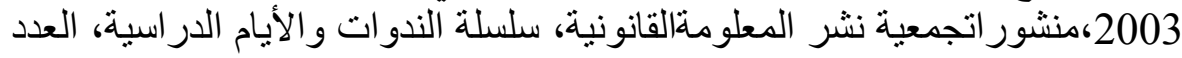

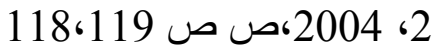
25-حكم الحكمة الإدارية بأكادير، عدد 497 بتاريخ 2005/11/24، ملف عدد .2004/754

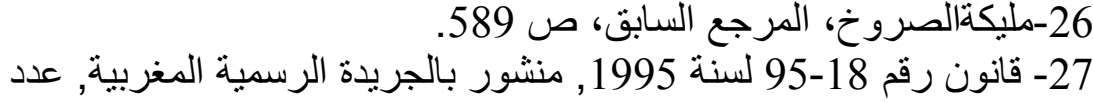
4336 بتاريخ رنغ 1995/11/29.

28-patrickRAMBAUD, Premiers enseignements des arbitrages duCIRDI: annuaire français de droit international, volume 28,1982, pp471-491.

$$
\begin{aligned}
& \text { 29- مصطفبونجة، نهال اللو اح، نفس المرجع، ص } 253 .
\end{aligned}
$$

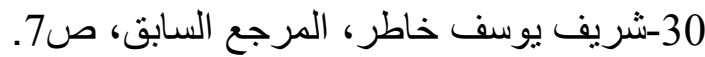

$$
\begin{aligned}
& \text { 31- نشر هذا القانون بالجريدة الرسميةالمصرية، العدد } 19 \text { (مكرر) الصادرفي } \\
& \text { 1998/05/08 } \\
& \text { 32- مليكة/الصروخ، المرجع السابق، ص 571. }
\end{aligned}
$$




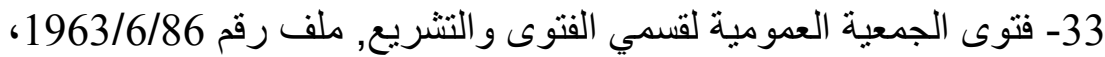

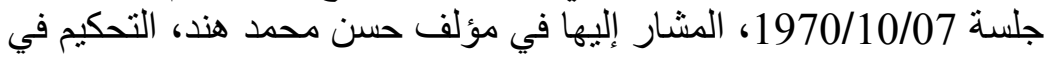

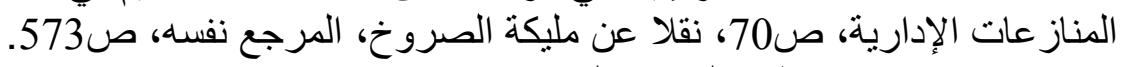

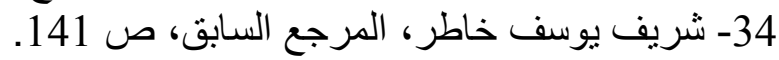

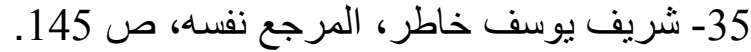

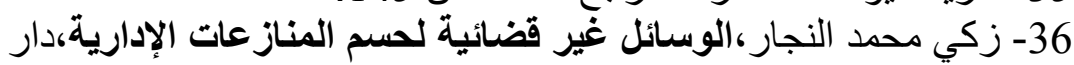

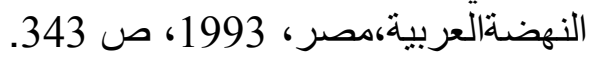
37- عزيمان عبد القادر، اتفاق التحكيم، دار النهضة العربية، 193 القية، الترة، مصر،

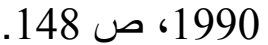

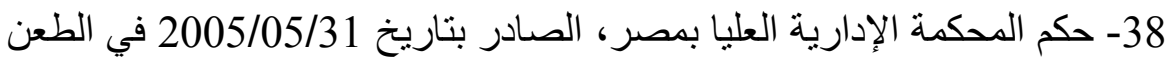

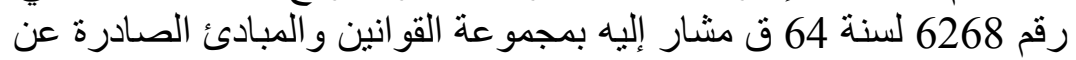

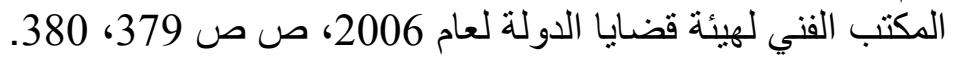

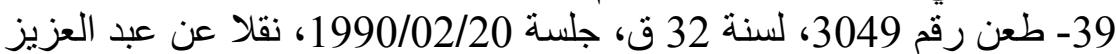

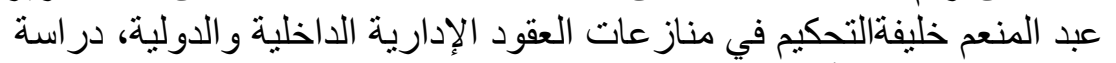

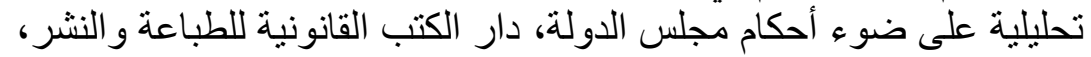

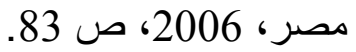
40- حكم محكمة القضاء بالقاهرة، الدائرة السادسة، عقود وتعويضات، الصادر

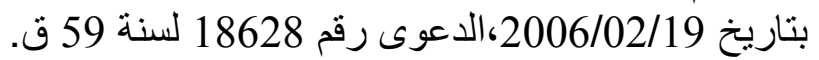
-نقلا عن: مصطفى بونجة، نهال اللواح، المرجع السابق، ص232. 